\title{
Current Advances in the Use of Nanophytomedicine Therapies for Human Cardiovascular Diseases
}

\author{
Mahvash Hesari (iD) \\ Pantea Mohammadi (iD' \\ Fatemeh Khademi id \\ Dareuosh Shackebaei (D) \\ Saeideh Momtaz iD ${ }^{2-5}$ \\ Narges Moasefi (i) \\ Mohammad Hosein Farzaei (D) ${ }^{6}$ \\ Mohammad Abdollahi (iD ${ }^{3,4}$ \\ 'Medical Biology Research Center, Health \\ Technology Institute, Kermanshah \\ University of Medical Sciences, \\ Kermanshah, Iran; ${ }^{2}$ Medicinal Plants \\ Research Center, Institute of Medicinal \\ Plants, ACECR, Tehran, Iran; ${ }^{3}$ Toxicology \\ and Diseases Group, Pharmaceutical \\ Sciences Research Center, The Institute \\ of Pharmaceutical Sciences (TIPS), Tehran \\ University of Medical Sciences, Tehran, \\ Iran; ${ }^{4}$ Department of Toxicology and \\ Pharmacology, School of Pharmacy, \\ Tehran University of Medical Sciences, \\ Tehran, Iran; ${ }^{5}$ Gastrointestinal \\ Pharmacology Interest Group, Universal \\ Scientific Education and Research \\ Network (USERN), Tehran, Iran; \\ 'Medical Technology Research Center, \\ Health Technology Institute, Kermanshah \\ University of Medical Sciences, \\ Kermanshah, Iran
}

Correspondence: Mohammad Hosein

Farzaei

Medical Technology Research Center,

Health Technology Institute, Kermanshah

University of Medical Sciences,

Kermanshah, 6734667/49, Iran

Emailmh.farzaei@gmail.com

Mohammad Abdollahi

Department of Toxicology and

Pharmacology, School of Pharmacy,

Tehran University of Medical Sciences,

Tehran, I4I76I44II, Iran

Email Mohammad@TUMS.Ac.Ir

\begin{abstract}
Considering the high prevalence of cardiovascular diseases (CVDs), the primary cause of death during the last several decades, it is necessary to develop proper strategies for the prevention and treatment of CVDs. Given the excessive side effects of current therapies, alternative therapeutic approaches like medicinal plants and natural products are preferred. Lower toxicity, chemical diversity, cost-effectiveness, and proven therapeutic potentials make natural products superior compared to other products. Nanoformulation methods improve the solubility, bioavailability, circulation time, surface area-to-volume ratio, systemic adverse side effects, and drug delivery efficiency of these medications. This study intended to review the functionality of the most recent nanoformulated medicinal plants and/ or natural products against various cardiovascular conditions such as hypertension, atherosclerosis, thrombosis, and myocardial infarction. Literature review revealed that curcumin, quercetin, and resveratrol were the most applied natural products, respectively. Combination therapy, conjugation, or fabrication of nanoparticles and nanocarriers improved the applications and therapeutic efficacy of herbal- or natural-based nanoformulations. In the context of CVDs prevention and/or treatment, available data suggest that natural-based nanoformulations are considerably efficient, alone or in blend with other herbal/synthetic medicines. However, clinical trials are mandatory to elucidate the safety, cardioprotective effect, and mechanism of actions of nanophytomedicines.
\end{abstract}

Keywords: cardiovascular diseases, medicinal plants, natural products, nanoformulation, nanoparticles

\section{Introduction}

Cardiovascular diseases (CVDs) are among the most significant and evergrowing concerns during the last several decades, accounting as the most lethal diseases worldwide. Approximately 17.7 million deaths were associated with CVDs in 2015 worldwide, corresponding to about $31 \%$ of all global death. Based on the World Health Organization (WHO) report, nearly 7.4 and 6.7 million deaths are caused by coronary heart diseases and stroke, respectively. ${ }^{1}$ The most common controllable risk factors for CVDs include a high degree of psychosocial factors, overconsumption of alcohol, the elevated value of low-density lipoprotein (LDL) and cholesterol, hypertension, insufficient consumption of fruits and vegetables, diabetes mellitus, abdominal obesity, smoking, and the lack of regular physical activity. $^{2,3}$ Combination of cholesterol, fat, calcium, and other harmful substances can form plaques, leading to atherosclerosis or hardening of the arteries. Depending on which vessels are affected by this process, cerebrovascular disease, coronary artery disease, cardiac arrhythmias, and the subsequent development of heart failure 
can occur. ${ }^{4}$ Although various kinds of therapies have emerged to control CVDs, most of them have not been sufficient to prevent or significantly reduce CVDs progression and prevalence. Considering the proven side effects of current therapies, the development of novel therapeutic strategies is emerging. ${ }^{5}$ Given the significance of nanotechnology, especially in medicine, it may be an innovative tool to prevent or cure CVDs. ${ }^{6}$

Since a long time ago, herbal products have been extensively utilized to tackle severe diseases. Besides, many pharmaceutical products are derived from plants. ${ }^{7,8,9}$ Enormous chemical diversity, low toxicity, therapeutic potentials, and cost-effectiveness make natural compounds precious to being exploited for discovering new therapeutic agents. ${ }^{7,10,11}$

Nanoformulation is a practical therapeutic approach to diminish the probable side effects of medications and enhance drug delivery efficiency. ${ }^{12}$ Encapsulation of natural products and their derivatives provides unique advantages, including reduced systemic adverse side effects, enhanced biosafety, high solubility and bioavailability of drugs, extended circulation time, and restricted accumulation in target organs. ${ }^{13,14}$ Different features of target organs can indicate the specific types of nanostructures that have to be designed to cure diseases. Diverse organic and inorganic nanostructures, including nanoparticles (NPs), have been developed to deliver phytochemicals such as curcumin, emodin, gymnemic acid, tilianin, puerarin, berberine, quercetin (QUE), scutellarin, magnolol, breviscapine, resveratrol, baicalin, naringenin, and so on. ${ }^{13,15}$ However, therapeutic applications of some natural products such as nano-curcumin or nano-resveratrol have been clarified. Data are nonetheless inadequate when it comes to CVDs. ${ }^{16,17}$ Considering the high prevalence of CVDs, the current study aimed to review the probable therapeutic advantages of nanophytomedicine for CVDs treatment. This article introduces medicinal plants and natural products that are favorable for CVDs prevention or treatment, along with the recent advances of natural-/ herbal-based nanoformulations, as efficient carriers for drug delivery against CVDs.

\section{Study Design}

Data were collected using several electronic databases, including Scopus, PubMed, and Google Scholar. Relevant in vitro and in vivo studies investigating the effects of natural-/herbal-based nanoformulations for CVDs management were collected until July 2020. This comprehensive review was performed using the following keywords: "cardiovascular disease", "cardiovascular disorder", "hypertension", "atherosclerosis", "thrombosis", "myocardial infarction", "coronary artery disease", "pulmonary arterial hypertension", "stroke", "ischemia reperfusion injury", "nanophytomedicine", "nanophytochemical", "natural product", "herbal extract", "medicinal plants", "nanomaterials", "nanoparticles", "nanoemulsion", "liposome", "micelle" in title/ abstract/keywords. To harmonize data, non-English language articles were excluded.

\section{Medicinal Plants and Phytochemicals in Cardiovascular Diseases}

Medicinal plants are defined as a medicine derived from parts of plants or a whole plant and constructed as a crude or purified form to treat or prevent disease. Phytochemicals or plant-derived natural products are chemicals that are produced through primary or secondary metabolism. The plants are a reservoir of primary or secondary metabolites that generally have biological activity and are suitable for pharmacological studies. ${ }^{18}$ A large group of medicinal plants known as alternative therapies for CVDs treatment is listed in Table 1. For example, it has been demonstrated that saponin components of Panax notoginsenoside, including ginsenoside $\mathrm{Rg} 1$, ginsenoside $\mathrm{Rg} 3$, ginsenoside $\mathrm{Rb}$, and notoginsenoside R1, can inhibit thrombosis, protect from ischemic myocardial cells, expand peripheral vessels, and prevent ischemic brain damage, etc. ${ }^{19}$ Moreover, cardioprotective activities of some phytochemicals such as silymarin, cyclovirobuxine $\mathrm{D}$, withanolides, curcumin, berberine, naringenin, tilianin, QUE, baicalin, resveratrol, allicin, and myricitrin were documented in various studies. ${ }^{20-34}$ Curcumin, a naturally phytoconstituent isolated from Curcuma longa rhizomes, was shown to have significant cardioprotective effects, including prevention of myocardial infarction, stroke, aortic aneurysm, and atherosclerosis. ${ }^{29,30}$ Also, it has been reported that anti-angiogenic drugs like allicin (significant phytochemicals present in garlic) might significantly involve the reproduction of clots in arteries that may cause a heart attack or stroke. ${ }^{25,35}$ QUE is a flavonoid present in different fruits and vegetables such as apples, citrus fruits, onions, and tea. ${ }^{36}$ Polymeric NPs of QUE considerably inhibited atherosclerosis. ${ }^{22}$ Myricitrin as a flavonol glycoside displayed anti-inflammatory, antioxidant, and anxiolytic effects. It can prevent vein endothelial cell dysfunction by regulating antioxidant enzyme 
Table I Medicinal Plants and Their Phytochemical Components Applied in the Treatment of CVDs

\begin{tabular}{|c|c|c|c|c|}
\hline Plant Name & Family & Phytochemicals & Actions & Reference \\
\hline Ginkgo biloba & Ginkgoaceae & $\begin{array}{l}\text { Iron-based superoxide dismutase, } \\
\text { sesquiterpenes, catechin, diterpen lactones, } \\
\text { ascorbic acid, flavonol, flavones glycosides, } \\
\text { ginkgolides, myricetin, quercetin, carotenoids }\end{array}$ & $\begin{array}{l}\text { Antistress activities, antiaging, cytotoxic, } \\
\text { antiulcer, anticoagulant, antidepressant, } \\
\text { hepatoprotective, memory enhancer, anti- } \\
\text { inflammatory, antimicrobial, antioxidants }\end{array}$ & {$[181,182]$} \\
\hline $\begin{array}{l}\text { Nerium } \\
\text { oleander }\end{array}$ & Apocynacea & $\begin{array}{l}\text { Dambonitol, deacetyloleandrin, I6-acetyl } \\
\text { gitoxigenin, oleandrigenin, scopoletin, scopolin, } \\
\text { oleandrin, ursolic acid, adyresin, odoroside, } \\
\text { neriantin, gitoxigenin, digitoxigenin, oleanolic acid, } \\
\text { nerium F, nerium D, neriodin, karabin, oleandrose, } \\
\text { neriodorein, uzarigenin, oleanolic acid, tannic acid }\end{array}$ & Cardioprotective agent, antioxidants & {$[183]$} \\
\hline $\begin{array}{l}\text { Terminalia } \\
\text { arjuna }\end{array}$ & Combretaceae & $\begin{array}{l}\text { Tannins, triterpenes, flavonoids, triterpenes, } \\
\text { arjunic acid, freidelin, b-sitosterol, polyphenols, } \\
\text { arjunetin }\end{array}$ & $\begin{array}{l}\text { Cardioprotective agent, antioxidants, } \\
\text { antimicrobial }\end{array}$ & {$[184,185]$} \\
\hline $\begin{array}{l}\text { Sesbania } \\
\text { grandiflora }\end{array}$ & Fabaceae & $\begin{array}{l}\text { Minerals, amino acids, nicotinic acid, riboflavin, } \\
\text { vitamin A, C }\end{array}$ & $\begin{array}{l}\text { Cardioprotective activities, } \\
\text { antiinflammatory, antimicrobial }\end{array}$ & {$[186]$} \\
\hline Centella asiatica & Apiaceae & $\begin{array}{l}\text { Asiatic acid, asiaticoside, triterpenes, bacogenin, } \\
\text { hydrocotylin, hersaponin, sitosterol, vallarine, } \\
\text { phenols, tannins }\end{array}$ & $\begin{array}{l}\text { Cardioprotective activities, anti- } \\
\text { inflammatory, antimicrobial, wound healing }\end{array}$ & {$[187]$} \\
\hline $\begin{array}{l}\text { Tinospora } \\
\text { cordifolia }\end{array}$ & Tinospora & $\begin{array}{l}\text { Berberine, diterpenoid lactones, sesquiterpenoids, } \\
\text { glycosides, steroids, palmarin, columbin, } \\
\text { chasmanthin, gilosterol, giloinin, tinosporol }\end{array}$ & Cardioprotective activity, antioxidant & {$[188,189]$} \\
\hline Bombax ceiba & Bombacaceae & $\begin{array}{l}\text { Sesquiterpenoids, n-triacontanol, } \\
\text { naphthoquinone, glycosides, lupeol, sitosterol, } \\
\text { flavonoids, tannins }\end{array}$ & $\begin{array}{l}\text { Cardioprotective activity, antioxidant, } \\
\text { antimicrobial }\end{array}$ & {$[190,191]$} \\
\hline Sonchus asper & Asteraceae & $\begin{array}{l}\text { Proanthocyanidin, sesquiterpenes, phenols, } \\
\text { tannins, niacin, thiamine, riboflavins, alkaloids, } \\
\text { flavonols, flavonoids, protein amino acids, } \\
\text { vitamins, minerals }\end{array}$ & $\begin{array}{l}\text { Cardioprotective activity, antitumor, anti- } \\
\text { inflammatory }\end{array}$ & {$[192,193]$} \\
\hline $\begin{array}{l}\text { Zingiber } \\
\text { officinale }\end{array}$ & Zingiberacae & 6-Gingerol, 6-shogaol, 8-gingerol, I0-gingerol. & $\begin{array}{l}\text { Cardioprotective impacts against stroke and } \\
\text { heart diseases, antimicrobial }\end{array}$ & [79] \\
\hline Syzygium cumini & Myrtaceae & Phenols, tannins, flavonoids, terpenes & $\begin{array}{l}\text { Cardioprotective, and antioxidant activities, } \\
\text { anti-inflammatory }\end{array}$ & {$[61]$} \\
\hline Prunus spp. & Rosaceae & Phenols & $\begin{array}{l}\text { Cardioprotective, and antioxidant activities, } \\
\text { anticancer anti- inflammatory, }\end{array}$ & [194] \\
\hline Paeonia emodi & Paeoniaceae & Tannins, terpenoids, carbohydrates, phenolics & $\begin{array}{l}\text { Cardioprotective, antioxidant, anti- } \\
\text { inflammatory, antimicrobial activities }\end{array}$ & {$[195]$} \\
\hline Pinus merkusii & Pine & $\begin{array}{l}\text { Saponins, triterpenoids, glycosides, alkaloids, } \\
\text { flavonoids, polyphenols }\end{array}$ & $\begin{array}{l}\text { Cardioprotective, anti-inflammatory } \\
\text { activities }\end{array}$ & [78] \\
\hline $\begin{array}{l}\text { Dracocephalum } \\
\text { moldavica }\end{array}$ & Labiatae & Rosmarinic acid, luteolin, tilianin & Cardioprotective, antioxidant activities & [69] \\
\hline $\begin{array}{l}\text { Panax } \\
\text { notoginsenoside }\end{array}$ & Araliaceae & $\begin{array}{l}\text { Ginsenoside RgI, ginsenoside Rg3, ginsenoside } \\
\text { RbI, notoginsenoside RI }\end{array}$ & $\begin{array}{l}\text { Cardioprotective, anti-inflammatory } \\
\text { activities }\end{array}$ & [19] \\
\hline
\end{tabular}


activity, reducing malondialdehyde and $\mathrm{H}_{2} \mathrm{O}_{2}$-induced oxidative damage. ${ }^{26,37}$ It has been demonstrated that encapsulation of berberine (an isoquinoline quaternary alkaloid) into liposomes could improve its efficacy by protecting cardiac function against myocardial infarction in vivo. ${ }^{31}$

\section{Nanoformulations as a Novel Drug Delivery Approach in Cardiovascular Diseases}

The stability, solubility, bioavailability, dissolution rate, and absorption are essential parameters affecting the efficiency of any drug in vivo. Nanotechnology can eliminate physical and biological barriers by applying nanophases and nanostructures at different science branches, mainly in nanomedicine and nano-based drug delivery systems. ${ }^{38}$ In the context of drug delivery, there are two main categories for nanostructured nanocarrier systems: organic nanocarriers (ie, micelle and vesicle nanocarriers, liposomes, polymeric nanogels, and dendrimers) and inorganic NPs (ie, metallic NPs like iron oxide and gold NPs, carbon nanotubes, quantum dots (QDs), and mesoporous silica NPs). ${ }^{39}$

Drug targeting means the ability of a drug molecule to accumulate at the sites of action, leading to a higher therapeutic index. Among various drug-targeting approaches, magnetic drug targeting (as a nanoparticle-based delivery system) is very useful. ${ }^{40,41}$ Functionalization of magnetic nanoparticles (MNPs) is possible through coating with different agents, including polymers, proteins, silane (or organosilane), silica, and other materials. For example, through supplying many amine groups, silanes construct an ideal system to tune the surface functionality of the $\mathrm{Fe} 3 \mathrm{O} 4$ NPs for protein conjugation. To enhance the stability of NPs against oxidation, surface coating with different polymers might be helpful. ${ }^{42}$

In the context of CVDs, a broad spectrum of therapeutic products is available for heart treatment following an ischaemic episode. Direct intramyocardial injection or intracoronary catheterization are common routes for delivering therapeutics to the myocardium with more certainty. ${ }^{43}$ Despite the positive outcomes of intramyocardial injection, it is an invasive technique that can severely damage the heart. On the other hand, intracoronary catheterization can induce embolization. Therefore, systemic intravenous injection of drugs is a superior alternative. This process is less invasive and provides a suitable condition for adequate drug circulation in the cardiovascular system. $^{43}$
Non-functionalized therapeutics are unable to target the heart specifically and are often cleared in reticuloendothelial organs. Therefore, drug encapsulation inside NPs enhances their persistence and circulatory half-lives compared with free form. For example, in hypertensive disease, intraduodenal administration of solid lipid NPs (SLN) loaded with nitrendipine (a calcium channel blocker) leads to three to four times more bioavailability than conventional formulations. ${ }^{44}$ SLNs are new favorable lipid-based nanocarriers that incorporate drugs in a solid hydrophobic core. ${ }^{39}$

In atherosclerosis, ruptures of macrophage-rich atherosclerotic plaques in the coronary arteries are the main reason underlying the sudden onset of acute coronary syndromes. Generally, targeted therapeutic interventions may inhibit macrophages' actions and reduce dosedependent adverse effects in remote organs. For instance, receptor-specific targeted vesicles loaded with statins, the most common cholesterol-lowering drugs, enhanced the possibility of high-dose treatment with efficient delivery and selective inhibition of highly active macrophages in vulnerable plaques. ${ }^{45}$

In acute myocardial infarction treatment, the limited regenerative capacity of cardiomyocytes and their slight ability for self-repair usually lead to permanent heart injuries. Hence, stem cell therapy is a useful approach to treat CVDs, but only less than $10 \%$ of the transplanted stem cells can remain at the targeted site. ${ }^{46}$ To overcome these drawbacks, iron oxide super-paramagnetic NPs have gained more attention. These NPs can be used in the orientation and proliferation tracking of stem cells. ${ }^{47}$

In thrombosis, systemic fibrinolytic therapy for recanalization of occluded vessels by intravenouslyadministration of the tissue plasminogen activator (tPA) was shown to have low efficacy and many side effects. In the rat model, magnetic NPs for tPA orientation to the target site enhanced the drug accumulation in the thrombus region. In another study, NPs operationalized with PPACK, a selective and irreversible thrombin inhibitor, improved circulation time, and antithrombotic activity of PPACK in an animal model. ${ }^{48}$

\section{Medicinal Plant-Based Nanoformulation for Cardiovascular Diseases}

Given the morbidity and mortality caused by CVDs, researchers have focused on discovering novel compounds 
and pharmacological targets to prevent or cure such conditions. Up to date, many medicinal plants have been traditionally used by the public as natural alternatives to synthetic drugs without any proof from clinical trials. ${ }^{49}$ Therefore, scientists are interested in developing natural products with validated efficacy and safety. Numerous herbal-based products are described to prevent and control CVDs. ${ }^{50}$ Various parts of the plants, from roots to flowers, have been used in this field. ${ }^{51}$

Furthermore, many drugs have been derived from herbal medicine's chemical constituents to develop commercial therapies for CVDs. ${ }^{52}$ Advances in nanomedicine and drug delivery systems improved the safety and efficacy of medicinal plant-based nanoformulations for CVDs. ${ }^{53,54}$ The following sections discuss the characteristics of medicinal plant-based nanoformulations that have been used for CVDs prevention or treatment. Physicochemical characteristics of NPs loaded with different medicinal plants and natural products for the treatment of CVDs are listed in Table 2. A schematic figure has also been provided to illustrate how nanophytomedicines affect CVDs (Figure 1).

\section{Rabdosia rubescens}

Rabdosia rubescens, also known as donglingcao, is a native herb from North China. ${ }^{55}$ In pathological conditions, P-selectin, an effector on activated human platelets, transfers from the $\alpha$-granule to the platelets membrane's surface and is converted into the soluble P-selectin (sPselectin) in the blood circulation, which ultimately leads to platelet aggregation and thrombosis. Therefore, the downregulation of sP-selectin has been considered to treat both inflammation and thrombosis. ${ }^{56,57}$ The capability of the aqueous extract of $R$. rubescens leaves (AERL) was investigated to determine the in vivo inhibition of thrombosis formation, in vitro platelet aggregation, and the in vitro P-selectin expression. AERL dose-dependently inhibited thrombosis in rats, inhibited platelet aggregation, and downregulated platelet sP-selectin release. Docking analysis exhibited that rosmarinic acid, the antithrombotic ingredient of AERL, was responsible for the downregulation of P-selectin expression. The minimal oral dose of AERL that inhibited thrombosis was $25 \mathrm{mg} / \mathrm{kg}$. The potency of AERL inhibiting thrombin-induced platelet aggregation was twofold, tenfold, and twelvefold higher than that of AERL inhibiting platelet aggregation induced by arachidonic acid, adenosine diphosphate, and plateletactivating factor, respectively. It was also reported that
$0.5 \mathrm{mg} / \mathrm{mL}$ of AERL forms NPs $(53-159 \mathrm{~nm}$ in diameter) in rat plasma. $^{58}$

\section{Syzygium cumini}

Syzygium cumini (S. cumini) is an evergreen tropical tree belonging to the Myrtaceae. Seeds of S. cumini have antidiabetic and gastro-protective properties. Previous studies have shown that the methanolic extract of $S$. cumini seeds was rich in phytochemicals with high antioxidative potential. ${ }^{59,60}$ The same extract reduced mitochondrial membrane potential and collagen content. It caused excessive production of reactive oxygen species (ROS) in $\mathrm{H} 9 \mathrm{C} 2$ cardiomyocytes, thereby suppressing the high glucoseinduced stress. ${ }^{61,62}$ Respecting this extract's antidiabetic and cardioprotective properties, the potential cardioprotective effect of $S$. cumini silver NPs (SmSNPs) was evaluated in glucose-induced cardiac stress in vitro. Silver NPs with higher safety were used to improve the delivery system and enhance the therapeutic potential of $S$. cumini against diabetic cardiomyopathy. SmSNPs were morphologically polydispersed and were consisted of irregular spherical contours. Restoration in cell size, nuclear morphology, and lipid peroxide formation observed following the treatment of glucose-stressed $\mathrm{H} 9 \mathrm{C} 2$ cardiac cells with SmSNPs. SmSNPs were stable, crystalline, and pure.

Meanwhile, they suppressed glucose-induced cardiac stress through cellular integrity maintenance and reduced oxidative damage. The HPLC analysis of the methanolic seed extract (MSE) has revealed that it was rich in QUE, p-coumaric acid, gallic acid, 3,4-dihydroxy benzoic acid, caffeic acid, sinapic acid, ferulic acid, kaempferol, chlorogenic acid, and p-hydroxybenzoic acid. The antioxidant assessment demonstrated that SmSNPs were more active than the $S$. cumini MSE alone. Pretreatment of glucose-stressed cells with SmSNPs restored the cell size and converted both the nuclear enlargement and DNA fragmentation to the normal state. Overall, administration of SmSNPs protected cardiac cells against glucose-induced stress by scavenging free radicals, maintaining cellular and nuclear integrity, and inhibiting lipid peroxide formation. ${ }^{63}$

\section{Cherry}

It is well known that cherries are rich in polyphenols, including flavonoids and anthocyanins. These polyphenols have been frequently used against human diseases such as cancers, heart disease, and diabetes. ${ }^{64,65}$ Beconcini et al investigated the ability of cherry extract (CE)-loaded NPs 
Table 2 Physicochemical Characteristics of NPs Loaded with Different Medicinal Plants and Natural Products for the Treatment of CVDs

\begin{tabular}{|c|c|c|c|c|c|c|}
\hline $\begin{array}{l}\text { Medicinal } \\
\text { Plants and } \\
\text { Phytochemicals }\end{array}$ & Nanoformulatin & $\begin{array}{l}\text { Average } \\
\text { Size }(\mathrm{nm})\end{array}$ & PDI & $\begin{array}{c}\text { Zeta } \\
\text { Potential } \\
(\mathbf{m V})\end{array}$ & Encapsulating Efficiency (\%) & Ref \\
\hline Ginger extract & $\begin{array}{l}\text { Polyurethane sample } \\
\text { with ginger extract }\end{array}$ & $90 \pm 9$ & $\sim 0.7$ & $+27.8 \pm 4.1$ & $\sim 82.9$ & {$[84]$} \\
\hline $\begin{array}{l}\text { Syzygium cumini } \\
\text { seeds }\end{array}$ & Syzygium cumini Ag NPs & $\sim 40-100$ & - & $-19.6 \pm 0.5$ & - & [63] \\
\hline $\begin{array}{l}\text { Dracocephalum } \\
\text { moldavica L. }\end{array}$ & TFDM-SLNs & $104.82 \pm 0.24$ & $0.21 \pm 0.97$ & $-28.7 \pm 1.94$ & $\begin{array}{l}\text { Luteolin, rosmarinic acid, and tilianin of } \\
\text { the optimal TFDM-SLNs formulation } \\
\text { were } 83.98 \pm 1.05,87.01 \pm 0.83 \text {, and } 88.82 \\
\quad \pm 0.58 \text {, respectively }\end{array}$ & {$[72]$} \\
\hline Paeonia emodi & Pe.EA40-AuNPs & $203.4 \pm 4.72$ & $0.32 \pm 0.01$ & - & - & {$[75]$} \\
\hline Curcumin & Curcumin nanoemulsion & $42.93 \pm 29.8$ & $0.36 \pm 0.04$ & $-0.12 \pm 0.50$ & $89.89 \pm 8.18 \%$ & {$[90]$} \\
\hline Curcumin & Curcumin/P & $\sim 30$ & - & - & - & [91] \\
\hline Curcumin & $\begin{array}{l}\text { Curcumin- polymer- } \\
\text { based nanoparticle }\end{array}$ & $30-100$ & - & - & - & [96] \\
\hline Curcumin & AC-Lipo & $192 \pm 0.8$ & - & $6.78 \pm 0.99$ & $79.33 \pm 3.61$ & {$[102]$} \\
\hline Curcumin & $\begin{array}{l}\text { Curcumin-mesoporous } \\
\text { silica material }\end{array}$ & $216.9 \pm 7.6$ & $\sim 0.4$ & - & $42 \pm 2.3$ & {$[107]$} \\
\hline Curcumin & Curcumin-PEG-PDLLA & $\sim 50$ & - & -14.9 & - & {$[108]$} \\
\hline Curcumin & $\begin{array}{l}\text { PLGA nanoparticle- } \\
\text { encapsulated curcumin }\end{array}$ & & - & -29 & - & {$[112]$} \\
\hline Curcumin & Curcumin/CMC-peptide & 331.2 & - & +11.2 & - & [94] \\
\hline Curcumin & $\begin{array}{l}\text { Curcumin-loaded } \\
\text { PEG-PDLLA NPs }\end{array}$ & $57.09 \pm 4.52$ & 0.19 & $0.44 \pm 0.018$ & $82.3 \pm 3.71$ & {$[110]$} \\
\hline Curcumin-nisin & $\begin{array}{l}\text { Curcumin-nisin poly } \\
\text { lactic acid NP }\end{array}$ & $284.0 \pm 17.9$ & - & - & - & {$[105]$} \\
\hline Cherry extract & $\begin{array}{l}\text { CE-loaded NPs based on } \\
\text { quaternary ammonium } \\
\text { chitosan } \\
\text { S-protected thiolated } \\
\text { derivative }\end{array}$ & $\begin{array}{l}344.9 \pm 17.8 \\
339.9 \pm 68.2\end{array}$ & $\begin{array}{l}0.52 \pm 0.08 \\
0.50 \pm 0.09\end{array}$ & $\begin{array}{l}14.8 \pm 0.3 \\
15.8 \pm 0.5\end{array}$ & $78.4 \pm 4.5$ & [66] \\
\hline Cherry extract & $\begin{array}{l}\text { FITC-QA-Ch NPs } \\
\text { FITC-QA-Ch-S-pro NPs } \\
\text { FITC-PLGA NPs }\end{array}$ & $\begin{array}{l}191.5 \pm 3.7 \\
235.4 \pm 3.2 \\
201.4 \pm 5.7\end{array}$ & $\begin{array}{l}0.30 \pm 0.02 \\
0.24 \pm 0.02 \\
0.06 \pm 0.05\end{array}$ & $\begin{array}{l}7.0 \pm 0.9 \\
5.5 \pm 0.8 \\
7.9 \pm 0.1\end{array}$ & - & [68] \\
\hline Cherry extract & $\begin{array}{l}\text { PLGA NP + CE } 100 \\
\text { PLGA NP + CE } 250 \\
\text { PLGA NP + CE } 420 \\
\text { PLGA NP + CE } 840\end{array}$ & $\begin{array}{c}216.0 \pm 2.6 \\
216.8 \pm 4.9 \\
208.4 \pm 4.9 \\
206.1 \pm 1.8\end{array}$ & $\begin{array}{l}0.06 \pm 0.03 \\
0.06 \pm 0.02 \\
0.05 \pm 0.02 \\
0.06 \pm 0.03\end{array}$ & $\begin{array}{l}-11.0 \pm 1.23 \\
-10.9 \pm 1.04 \\
-12.6 \pm 0.87 \\
-8.36 \pm 1.07\end{array}$ & $\begin{array}{c}- \\
64.8 \pm 2.3 \\
43.9 \pm 4.6 \\
79.8 \pm 6.2\end{array}$ & [67] \\
\hline Pinus merkusii & Chitosan-Pinus merkusii & $201.8 \pm 14.6$ & - & - & - & [78] \\
\hline Ginsenoside Rg3 & P-Rg3 & $49.44 \pm 0.15$ & $0.339 \pm 0.001$ & - & $96.47 \pm 1.92$ & {$[115]$} \\
\hline
\end{tabular}

(Continued) 
Table 2 (Continued).

\begin{tabular}{|c|c|c|c|c|c|c|}
\hline $\begin{array}{l}\text { Medicinal } \\
\text { Plants and } \\
\text { Phytochemicals }\end{array}$ & Nanoformulatin & $\begin{array}{l}\text { Average } \\
\text { Size (nm) }\end{array}$ & PDI & $\begin{array}{c}\text { Zeta } \\
\text { Potential } \\
(\mathrm{mV})\end{array}$ & Encapsulating Efficiency (\%) & Ref \\
\hline $\begin{array}{l}\text { Panax } \\
\text { notoginsenoside }\end{array}$ & PNS-HLV & $337.8 \pm 40.2$ & - & $-44.7 \pm 0.5 \mathrm{I}$ & $\begin{array}{l}\text { RI: } 57.5 \pm \mathrm{I} . \mathrm{I} \\
\mathrm{RbI}: 83 . \mathrm{I} \pm \mathrm{I} .7 \\
\mathrm{RgI}: 40.5 \pm \mathrm{I} .8\end{array}$ & [119] \\
\hline $\begin{array}{l}\text { Salvianolic acid } \\
\text { B and panax } \\
\text { notoginsenoside }\end{array}$ & RGD-S/P-LPNs & $139.5 \pm 4.1$ & $0.16 \pm 0.04$ & $-32.4 \pm 3.7$ & $\begin{array}{l}\text { Sal B: } 90.3 \pm 3.7 \\
\text { PNS: } 89.1 \pm 3.2\end{array}$ & {$[12 \mid]$} \\
\hline Berberine & BB-lip & $\sim 0.11$ & $\sim 0.048$ & - & - & {$[31]$} \\
\hline Tilianin & $\begin{array}{l}\text { Tilianin-loaded PEG-PPS } \\
\text { micelles }\end{array}$ & $\sim 70$ & - & -2.73 & - & {$[134]$} \\
\hline Puerarin & PUE@PEG-PE micelles & $\sim 16.0$ & & $-24.1 \mathrm{ev}$ & 68.7 & [139] \\
\hline Puerarin & $\begin{array}{l}\text { PUE@TPP/PEG-PE } \\
\text { micelles }\end{array}$ & $\sim 17.1$ & $<0.2$ & -6.24 & $\sim 85.5$ & {$[140]$} \\
\hline Puerarin & RGD/PEG-PUE- SLN & $110.5 \pm 3.4$ & $0.23 \pm 0.03$ & $-26.2 \pm 1.8$ & $85.7 \pm 2.7$ & [143] \\
\hline Naringenin & $\begin{array}{l}\text { Naringenin lipid } \\
\text { nanoemulsions }\end{array}$ & $\sim 200$ & $\sim 0.2$ & - & - & {$[|3|]$} \\
\hline Baicalin & BN-PEG-NLC & $83.9 \pm 1.6$ & $0.21 \pm 0.06$ & $-32.1 \pm 1.8$ & $83.5 \pm 1.2$ & [153] \\
\hline Quercetin & $\mathrm{mRQ}$ & $22.34 \pm 0.15$ & $\begin{array}{l}0.111 \pm \\
0.001\end{array}$ & - & - & [148] \\
\hline Quercetin & Quercetin-loaded PLGA & $343.5 \pm 25.4$ & - & - & - & [22] \\
\hline Quercetin & PLGA-quercetin & $165 \pm 75$ & - & $-288 \pm 12$ & $9815 \pm 05$ & [149] \\
\hline Breviscapine & Bre-LE & $225.3 \pm 8.8$ & $0.22 I \pm 0.020$ & $-29.6 \pm 1.5$ & $94.5 \pm 0.6$ & {$[161]$} \\
\hline Resveratrol & RSV-NC & $207 \pm 0.03$ & $0.12 \pm 0.04$ & $-7.15 \pm 0.19$ & $99.54 \pm 1.02$ & [156] \\
\hline Resveratrol & $\mathrm{mRC}$ & $25.05 \pm 0.53$ & $0.059 \pm 0.01$ & - & - & [157] \\
\hline Resveratrol & RS-SLN & $\sim 271.13$ & - & $-25.8 \pm 0.33$ & - & [158] \\
\hline $\begin{array}{l}\text { Epigallocatechin- } \\
\text { 3-Gallate }\end{array}$ & L-Enano & $104.8 \pm 0.4$ & $0.18 \pm 0.020$ & $\begin{array}{c}-20.30 \pm 1.5 \\
-21.81 \pm 1.18\end{array}$ & $\sim 96$ & [173] \\
\hline $\begin{array}{l}\text { Epigallocatechin- } \\
\text { 3-Gallate }\end{array}$ & CSNLCE & $\begin{array}{l}53.5 \pm 1.6 \\
53.5 \pm 1.6\end{array}$ & $\begin{array}{l}0.19 \pm 0.01 \\
0.19 \pm 0.01\end{array}$ & $\begin{array}{l}13.3 \pm 1.0 \\
13.3 \pm 1.0\end{array}$ & $\sim 99$ & [174] \\
\hline Magnolol & Magnolol NPs & $75.6 \pm 1.7$ & $0.24 I \pm 0.023$ & - & $\sim 96.4$ & [169] \\
\hline Magnolol & $\begin{array}{l}\text { EPC- encapsulated } \\
\text { magnolol }(0.01 \mathrm{mg} / \mathrm{mL}) \\
\text { DPPC- encapsulated } \\
\text { magnolol }(0.01 \mathrm{mg} / \mathrm{mL})\end{array}$ & $\begin{array}{l}54.7 \\
27.5\end{array}$ & - & - & $\begin{array}{l}74.13 \pm 1.86 \\
64.26 \pm 2.92\end{array}$ & [168] \\
\hline Tanshinone IIA & $\begin{array}{l}\text { Discoidal recombinant } \\
\text { HDL } \\
\text { Spherical recombinant } \\
\text { HDL }\end{array}$ & $\begin{array}{l}138.2 \pm 5 . \mid \\
132.6 \pm 4.8\end{array}$ & - & $\begin{array}{l}-^{18.2 \pm 0.6} \\
-35.6 \pm 0.8\end{array}$ & $\begin{array}{l}93.3 \pm 1.5 \\
98.5 \pm 1.2\end{array}$ & [178] \\
\hline
\end{tabular}


Table 2 (Continued).

\begin{tabular}{|c|c|c|c|c|c|c|}
\hline $\begin{array}{l}\text { Medicinal } \\
\text { Plants and } \\
\text { Phytochemicals }\end{array}$ & Nanoformulatin & $\begin{array}{c}\text { Average } \\
\text { Size (nm) }\end{array}$ & PDI & $\begin{array}{c}\text { Zeta } \\
\text { Potential } \\
(\mathbf{m V})\end{array}$ & Encapsulating Efficiency (\%) & Ref \\
\hline Tanshinone IIA & TPP-TPGS/TN/LPNs & $\sim 140$ & $0.16 \pm 0.03$ & $\sim-10$ & $\sim 90$ & {$[179]$} \\
\hline Tanshinone IIA & IIA-NP & $100-200$ & $<0.25$ & $-7.12 \pm 0.07$ & $61.30 \pm 1.96$ & {$[180]$} \\
\hline
\end{tabular}

Abbreviations: $\mathrm{Ag}$, argentums (silver); TFDM-SLNs, total flavonoid extract from D. moldavica L. solid lipid nanoparticles; Pe.EA40-AuNPs, P. emodi ethyl acetate fractiongold nanoparticles; curcumin/P, curcumin/PBLG-PEG-PBLG (poly (gamma-benzyl-L-glutamate)-poly(ethylene glycol)-poly(gamma-benzyl-L-glutamate) (PBLG-PEG-PBLG)); AC-Lipo, liposomes loaded with atorvastatin calcium and curcumin; curcumin-PEG-PDLLA, curcumin-poly(ethylene glycol) methyl ether-block-poly(D,L- lactide); curcumin/ CMC-peptide, curcumin encapsulated by carboxymethyl chitosan (CMC) nanoparticle conjugated to a myocyte-specific homing peptide; curcumin-loaded PEG-PDLLA NPs, curcumin-loaded monomethoxy poly (ethylene glycol)-b-poly (DL-lactide) nanoparticles; PLGA, poly lactic-co-glycolide; CE, cherry extract; FITC-QA-Ch NPs, fluorescein isothiocyanate-quaternary ammonium chitosan nanoparticles; FITC-QA-Ch-S-pro NPs, fluorescein isothiocyanate-quaternary ammonium chitosan S-protected thiolated derivative; P-Rg3, Rg3-loaded Pluronic FI27 micelles; PNS-HLV, panax notoginsenoside-loaded core-shell hybrid liposomal vesicles; RGD-S/P-LPNs, arginyl-glycyl-aspartic acid-salvianolic acid B/panax notoginsenoside-loaded lipid-polymer hybrid nanoparticles; BB-lip, berberine liposomes; PEG-PPS, poly(propylene sulfide)-co-poly(ethylene glycol); PUE@PEG-PE, puerarin-loaded I,2-distearoyl-sn-glycero-3-phosphoethanolamine-N-[methoxy(polyethylene glycol)-2000]; TPP, triphenylphosphonium; RGD/PEGPUE- SLN, RGD-modified and PEGylated solid lipid nanoparticles loaded with puerarin; BN-PEG-NLC, baicalin-loaded PEGylated nanostructured lipid carriers; mRQ, resveratrol and quercetin in Pluronic ${ }^{\circledR}$ F- 127 micelles; Bre-LE, breviscapine lipid emulsion; RSV-NC, resveratrol nanocapsule; mRC, resveratrol-curcumin at a molar ratio of 5:I in FI27 micelles; RS-SL, a solid lipid nanoparticle loaded with resveratrol; L-Enano, ligand-epigallocatechin-3-gallate-loaded nanoparticles; CSNLCE, chitosan-coated EGCG encapsulated nanostructured lipid carriers; EPC, I,2-diacyl-sn-glycero-3-phosphocholine; DPPC, I,2-dipalmitoyl-sn-glycero-3-phosphocholine; TPP-TPGS/TN/LPNs, triphenylphosphonium-D- $\alpha$-tocopheryl polyethylene glycol 1000 succinate surface-modified, tanshinone-loaded LPNs; IIA-NP, tanshinone IIA nanoparticles.

to improve the resistance of endothelial cells against oxidative stress. ${ }^{66} \mathrm{CE}$-loaded NPs were prepared using both quaternary ammonium chitosan (NP1; QA-Ch-NP) and an S-protected thiolated derivative (NP2; QA-Ch-S-pro-NP). The CE-encapsulated NPs protected human umbilical vein endothelial cells (HUVECs) against oxidative stress, and both types of NPs improved the CE permeation parameters compared with control. Of course, CE-loaded NP2 reduced ROS production more effectively than CEloaded NP1 and free CE. ${ }^{66}$ It was also shown that CE polyphenols encapsulated in chitosan derivatives (Ch-der) mucoadhesive NPs were more effective antioxidant protectors than PLGA NPs. When higher therapeutic doses are needed, PLGA NPs are preferred due to less cytotoxicity. ${ }^{67}$ It is also reported that similar to dexamethasone, CE can reduce the production of inflammatory cytokines. The anti-inflammatory properties of $\mathrm{CE}$, either encapsulated in NPs PLGA or Ch-der or free form, have been evaluated on lipopolysaccharide (LPS)-stressed HUVECs. CE-loaded QA-Ch-NPs were the most effective NPs, by increasing the in vitro anti-inflammatory activity of $\mathrm{CE}$ through reducing the secretion of prostaglandin $\mathrm{E}_{2}$, tumor necrosis factor-alpha (TNF- $\alpha$ ), and interleukin 6 (IL-6) cytokines, and by enhancing the IL-10 level. CEloaded QA-Ch-NPs also declined the nucleotide-binding domain and leucine-rich repeat receptor family, pyrin domain-containing protein 3 inflammasome, and nitric oxide, which was implicated in the internalization of the extract into HUVECs. ${ }^{68}$ Therefore, nanoformulation can protect $\mathrm{CE}$ from degradation in the gastrointestinal tract.

\section{Dracocephalum moldavica}

Dracocephalum moldavica L. belongs to the Labiatae family. It was shown to have therapeutic efficacy for hypertension, atherosclerosis, and coronary heart disease. Total flavonoid of D. moldavica (TFDM) include tilianin, luteolin, and rosmarinic acid, which play critical roles in D. moldavica pharmacological action. ${ }^{69-71}$ In another study, the effectiveness of TFDM solid lipid NPs (TFDMSLNs) were investigated against coronary artery occlusion-induced myocardial ischemia-reperfusion injury rats. $^{72}$ The central composite design and response surface method were used to optimize the formulation of TFDMSLNs. TFDM-SLN-treated group showed smaller infarct size, lower LDH activity, and lower CK level, indicating an improved cardioprotective effect of TFDM-SLN compared with TFDM alone. Administration of the TFDMSLN improved the integrity of the myocardial membrane and fibers while significantly reduced the IL- $1 \beta$ and TNF$\alpha$ levels. $^{72}$

\section{Paeonia emodi}

Paeonia emodi Wall. Ex Royle. belongs to the Paeoniaceae family. It has been used for the treatment of cardiac diseases such as atherosclerosis, hypertension, congestive heart failure, and palpitations. ${ }^{73}$ Ibrar et al reported cardioprotective activity of $P$. emodi ethyl acetate fraction (Pe.EA) in the reduction of alanine aminotransferase (ALT), AST, LDH, and CPK. Pe.EA also possessed antithrombosis, free radical scavenging, and antihyperlipidemic effects. ${ }^{74}$ In another study, Pe gold NPs significantly 


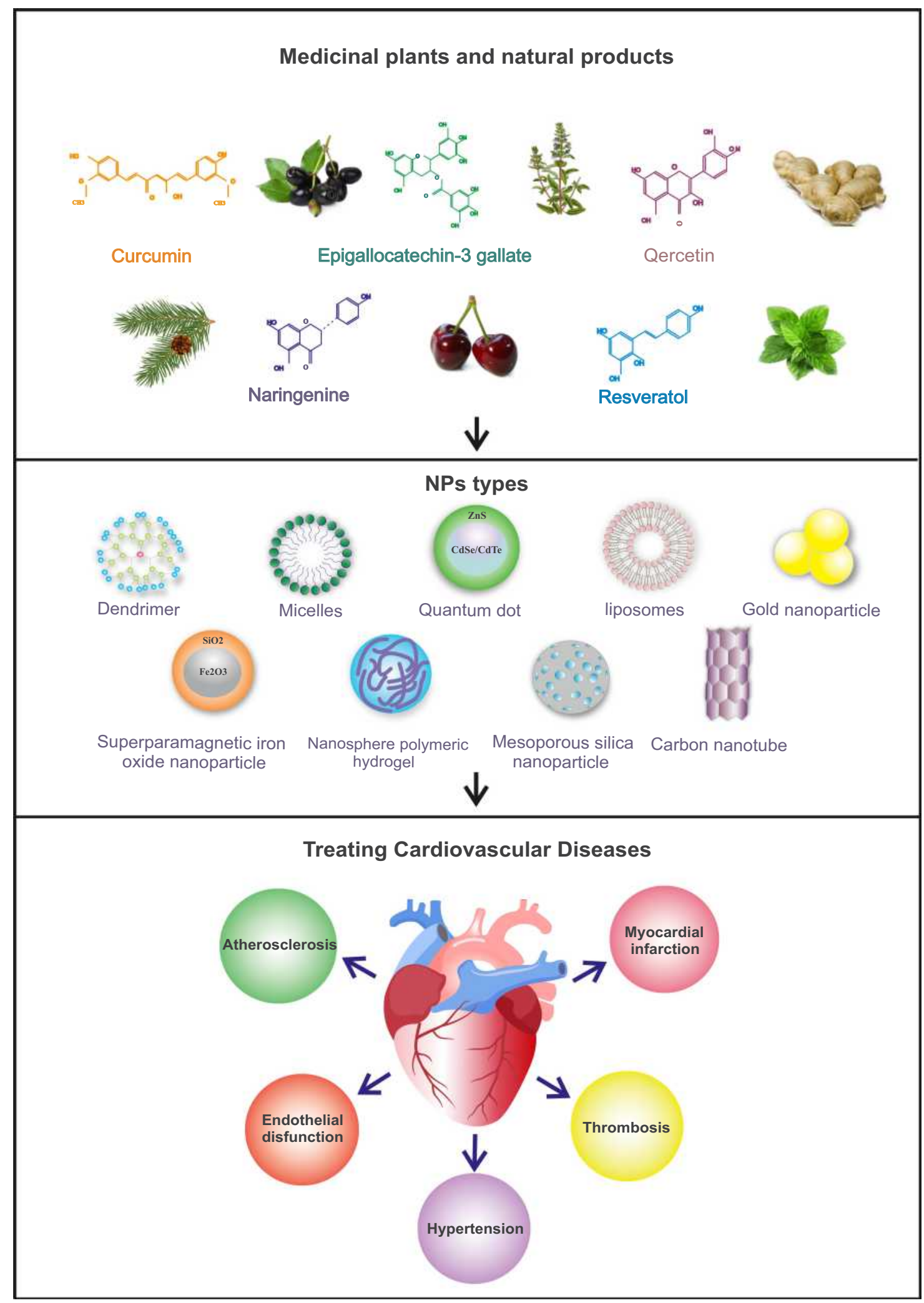

Figure I A schematic figure illustrating the effect of nanophytomedicine on cardiovascular diseases. 
reduced lipid profile, ALT, AST, CPK, LDH, and DNA damage in mice. ${ }^{75}$

\section{Pinus merkusii}

Pinus plant contains phytochemicals such as polyphenols, lignans, alkaloids, flavonoids, saponins triterpenes, glycosides, sterols, and triterpenoids. ${ }^{76,77}$ It was shown that administration of chitosan- $P$. merkusii extract NPs (400 mg/kg BW) significantly decreased the LDH, MDA, and CK-MB levels in heart tissue. These NPs also considerably increased the SOD and GPx levels and inhibited the formation of ROS and oxidative damage in myocardial cells. Thus, Pinus NPs could prevent lead acetate-induced cardiac cell damage through scavenging free radicals and enhancing antioxidant enzymes. ${ }^{78}$

\section{Ginger}

The ginger extract, derived from the rhizome of Zingiber officinale, is being used against heart diseases and stroke, bacterial infections, malabsorption, nausea, vomiting, and indigestion. ${ }^{79}$ Verma et al reported the protective effect of ginger powder against CVDs could be associated with enhancement of fibrinolytic activity and decrease of lipid peroxidation in atherosclerosisinduced rabbits. ${ }^{80}$ Synergetic effects of ginger powder and nifedipine have also been shown on antiplatelet aggregation in hypertensive patients. ${ }^{81}$ Furthermore, the beneficial effects of chemical components of ginger on blood glucose levels, blood pressure, and lipid concentrations have been stated. ${ }^{82,83} \mathrm{~A}$ mixture of polyesterand polyether-urethanes (PU) and the ethanolic extract of ginger root (containing 6-shogaol, 6-gingerol, 8-gingerol, and 10-gingerol) was used to prolong the time of the constant release of the extract from NPs. The membrane penetration of ginger extract-polymer NPs was assessed using a polyvinylidene fluoride artificial membrane. It was shown that the PU NP degradation started after 2 days. The extract passed through this membrane after 3-4 days. The rise of stability against hydrolysis could explain the delayed degradation due to encapsulation. The products were heat resistant up to $280^{\circ} \mathrm{C}$, and the PU NPs with and without ginger extract did not irritate murine skin in vivo testing. Borcan et al proposed that PU NPs could be a cardiovascular protector. $^{84}$

\section{Natural Product-Based \\ Nanoformulations for Cardiovascular Diseases}

Flavonoids, phenolic acids, hydroxyl cinnamic acids, organosulfides, alkaloids, carotenoids, isoflavones, anthocyanins, terpenes, and phytosterols are the main categories of phytochemicals. These phytochemicals have a broad spectrum of medical values against different diseases. Antioxidative, antiangiogenic, antiischemic, antihypercholesterolemic, inhibition of platelet aggregation, and antiinflammatory activities of isoflavones, QUE, catechin, resveratrol, carotenoids, and sulforaphane have been stated for cardioprotection and reduction of CVDs. ${ }^{84,85}$ This review has also provided a brief overview of recent advances in natural product-based nanodrugs to treat CVDs. The mechanisms of action of nanophytomedicines are illustrated in Figure 2.

\section{Curcumin}

It was comprehensively reviewed that curcumin exerts antioxidant activity and is functional against oxidative stress-induced damages. ${ }^{86-89}$ Rachmawati et al evaluated the antihypercholesterolemic and antihypertensive effects of curcumin nanoemulsion in vitro using acetylcholinesterase (ACE) and 3-hydroxy-3-methylglutaryl coenzyme A reductase (HMGR) assay kits. The results revealed that nanoemulsified curcumin slightly increased its inhibitory effect on ACE compared with pure curcumin. Furthermore, curcumin nanoemulsion increased the HMGR inhibition, representing its antihypercholesterolemic activity. ${ }^{90}$ In another study, the encapsulation of curcumin into multipolymer poly (gamma-benzyl -L-glutamate)-poly(ethylene glycol)-poly (gamma-benzyl -L-glutamate), known as PBLG-PEG-PBLG, improved its water solubility, biological activity, and dispersion in aqueous solutions in a diabetic cardiomyopathy model. In vivo administration of curcumin/P enhanced the serum levels of $\mathrm{H} 2 \mathrm{~S}$ and $\mathrm{Ca}^{2+} \mathrm{i}$ content in myocardial cells and upregulated the expression of cystathionine- $\gamma$-lyase, calmodulin, and calcium-sensing receptor. Furthermore, curcumin and curcumin/P significantly reduced diabetic cardiomyopathy and alleviated pathological and morphological destruction of myocardial cells. ${ }^{91}$ Cardioprotective effects of curcumin NPs were also shown in ISO-induced AMI in diabetic rats, attributed to their antioxidant and anti-inflammatory features. ${ }^{92}$ On the other hand, two nanoformulation of curcumin; 1) curcumin encapsulated in 


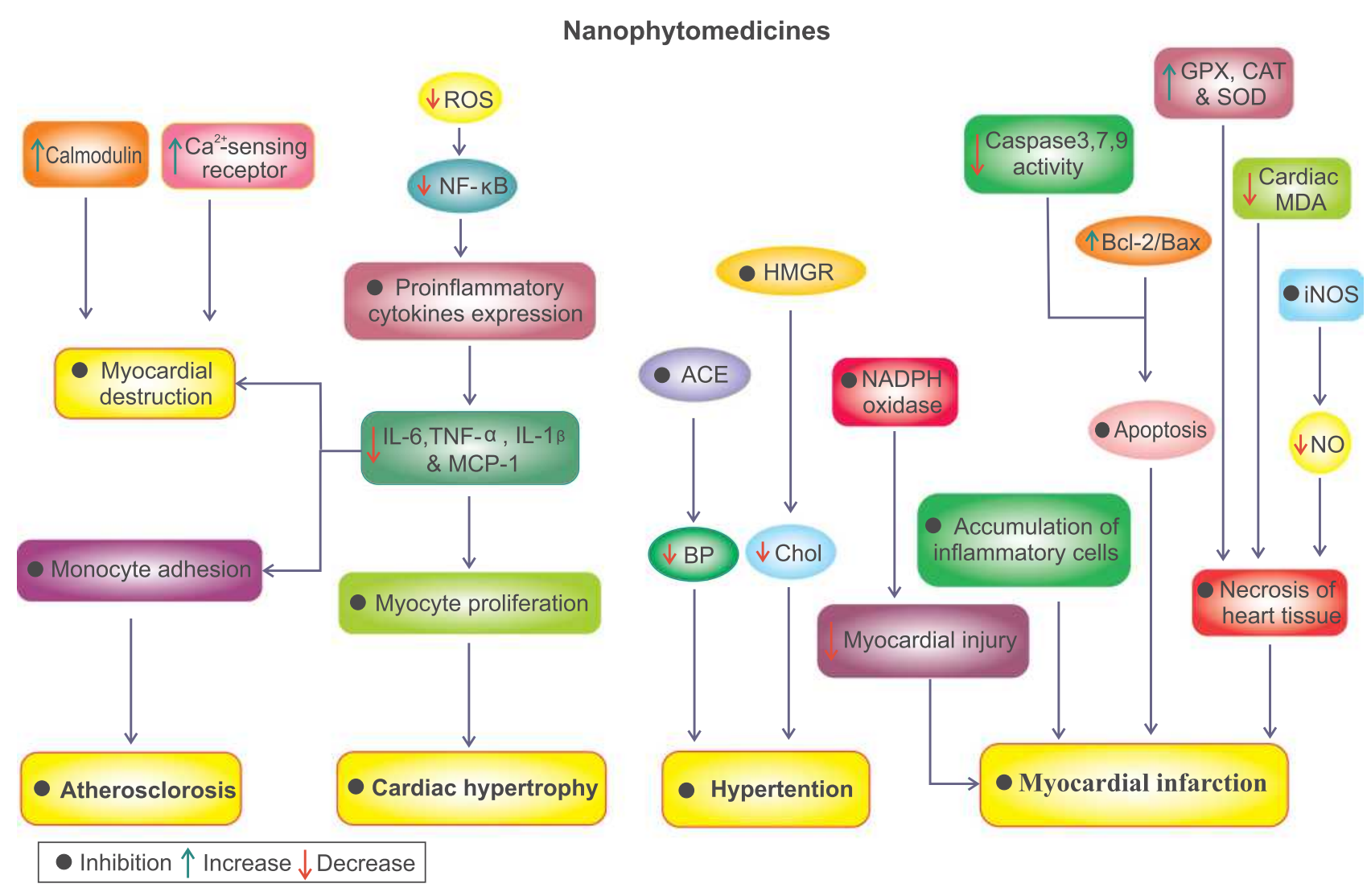

Figure 2 The nanophytomedicines mechanism of action in CVDs therapy.

Abbreviations: ROS, reactive oxygen species; NF- $\mathrm{kB}$, nuclear factor kappa B; ACE, acetylcholinesterase; HMGR, 3-hydroxy-3-methylglutaryl coenzyme Areductase; BP, blood pressure; Chol, cholesterol; IL-6, interleukin 6; IL-I $\beta$, interleukin I $\beta$; TNF- $\alpha$, tumor necrosis factor-alpha; MCPI, monocyte chemotactic protein I; iNOS, inducible nitric oxide synthase; SOD, superoxide dismutase; GPX, glutathione peroxidase; CAT, catalase; NADPH oxidase, nicotinamide adenine dinucleotide phosphate oxidase; MDA, malondialdehyde.

poly (glycidyl methacrylate) NPs alone (Cur-PGMA), and 2) curcumin in combination with a peptide targeting the $\alpha$-interacting domain of L-type $\mathrm{Ca}^{2+}$ channel (CurAIDPGMA); were investigated against ischemiareperfusion injury in rat hearts. ${ }^{93}$ Both NPs were found effective against ischemia-reperfusion-induced oxidative stress and myocardial injury. Another study revealed that curcumin encapsulation in carboxymethyl chitosan NPs (Cur-CMC) increased its bioavailability, maintained its bioactivity, and reduced cardiac hypertrophy in a rat model. ${ }^{94}$ Curcumin NPs were used for the treatment of monocrotaline-induced pulmonary arterial hypertension in the rat model. Treatment with curcumin NPs $(50 \mathrm{mg} / \mathrm{kg}$ i. p.) attenuated the development of right ventricular hypertrophy, decreased right ventricle weight to the bodyweight ratio, decreased right ventricle mRNA expression of TNF$\alpha$, and IL-1 $\beta$, and diminished oxidative stress. ${ }^{95}$

Pretreatment with curcumin polymer-based NPs solution $(\mathrm{nC})$ and curcumin solution $(\mathrm{Cs})$ was investigated in ISO hydrochloride (ISO)-induced myocardial infarction rats. Neither $\mathrm{Cs}$ nor $\mathrm{nC}$ influenced systolic or diastolic blood pressure values before or after ISO administration. Pretreatment with different doses of $\mathrm{Cs}$ and $\mathrm{nC}$ increased RR interval and reduced the heart rate before ISO administration. However, the mechanism by which curcumin reduced the heart rate remained unknown. The highest dose of $\mathrm{Cs}$ and $\mathrm{nC}(200 \mathrm{mg} / \mathrm{kg} \mathrm{bw})$ was more effective for cardioprotection. ${ }^{96}$ Pretreatment of $\mathrm{Cs}$ and $\mathrm{nC}$ reduced lipid peroxidation, myocardial levels of MDA, nitric oxide, and total oxidative status. A lower level of nitric oxide was obtained in $\mathrm{nC}$ pretreated rats. Administration of both $\mathrm{Cs}$ and $\mathrm{nC}$ lowered the serum LDH, ALT, and AST levels in ISO-induced rats, but $\mathrm{nC}$ was more active. ${ }^{96}$ Lipopolymer hybrid NPs of curcumin have also been used to protect against QT prolongation. ${ }^{97}$ In another investigation by Boarescu et al, pretreatment of rats with $\mathrm{Cs}$ and $\mathrm{nC}$ reduced severe myocardial tissue damage, myofibrillar degeneration, interstitial edema, and accumulation of inflammatory cells and necrosis. ${ }^{98}$ Overall, the administration of $\mathrm{nC}$ was suggested to prevent the 
extension of myocardial tissue damages in acute myocardial infarction.

Inflamed endothelium is involved in atherosclerosis development and targets antiatherosclerosis therapy to treat hyperlipidemia and/or inflamed endothelial cells. Atorvastatin calcium, an antiatherosclerosis drug, acts through reducing plasma lipids and intimal hyperplasia, promoting intimal regeneration, and inhibiting the intimal smooth muscle cell accumulation. ${ }^{99,100}$ As mentioned, the antiatherosclerosis activity of curcumin is attributed to its anti-inflammatory and antioxidant activities. ${ }^{101}$ Combination of atorvastatin calcium and curcumin synergistically reduced atherosclerosis and diminished the side effects of atorvastatin in both in vitro and in vivo models. ${ }^{102}$ Another study showed that E-selectin-binding (Esb) peptide-modified PEG-1, 2-distearoyl-sn-glycerol -3-phosphoethanolamine (DSPE) (Esb-PEG-DSPE) liposomes loaded with atorvastatin and curcumin (T-ACLipo) inhibited E-selectin and the intercellular cell adhesion molecule-1 gene expression; increased antioxidative effects; and led to much weaker fluorescence staining of IL-6 and monocyte chemotactic protein 1 (MCP1) in comparison with either single-drug treatment. T-AC-Lipo treatment also reduced total cholesterol and LDL. Overall, it was demonstrated that T-AC-Lipo can reduce atherosclerosis by decreasing lipid deposition. ${ }^{102}$ Administration of nano-curcumin and aged garlic extract (AGE) reduced advanced glycation end products (AGEPs) and oxidative stress in streptozotocin-induced diabetic rats. Nanocurcumin and AGE suspension attenuated myocardial cell deaths, myocardial fibrosis, and cardiac inflammation by inhibiting oxidative stress and AGEPs accumulation in diabetic heart tissues. Although nano-curcumin upregulated the Mn-SOD and downregulated the AGEPs gene expressions, AGE was more potent. ${ }^{103}$

Nisin, an antimicrobial peptide, induced cell cycle arrest and apoptosis while reducing the head and neck squamous cell carcinoma cells. ${ }^{104}$ A nanoformulation of nisin and curcumin was used to improve their delivery, stability, bioavailability, and pharmacological activity for CVDs treatment. Curcumin-nisin nanoparticle (CurNisNp) was found non-toxic and well-tolerated in mammals. Pretreatment of myocardial infarction of ISO-induced guinea pigs with CurNisNp (21 mg/kg) improved ECG patterns, suppressed the serum myeloperoxidase activity, reduced ROS and MDA levels, and downregulated cardiac troponin I expression in the heart. Moreover, CurNisNp improved the hypertrophy index, necrosis, myofibril thickness, and loss of transverse striations. ${ }^{105}$ In another study, a surfactant-soluble oral drug delivery system (DDS) was prepared to increase the curcumin absorption. DDS curcumin reduced perivascular fibrosis, myocardial cell diameter, and hypertrophy following myocardial infarction in rats. Pretreatment with DDS curcumin $(0.5 \mathrm{mg} / \mathrm{kg} / \mathrm{d}$, oral $)$ significantly reduced the posterior wall thickness and improved the rats' systolic function. ${ }^{106}$ The effect of curcumin-loaded mesoporous silica NPs (MSNs) was assessed against doxorubicininduced cardiotoxicity in rats. Pretreatment with curcumin-MSNs significantly protected myocardium from the toxic effects of repeated administration of doxorubicin by reducing the level of MDA and increasing SOD, GSH, and catalase levels in cardiac tissue. Curcumin-MSNs pretreated groups showed lower ALP levels, CPK, MDA, and LDH than those only treated with doxorubicin. The histology of heart tissues demonstrated more preservation of myofibrils and the cytoplasm vacuolization in the curcumin-MSNs+doxorubicin treated group. The cardioprotective activity of curcumin-MSNs could be attributed to enhanced bioavailability and its significant antioxidant and anti-inflammatory activities. ${ }^{107}$

According to another study conducted by $\mathrm{Li}$ et al, exposure of cardiomyocytes to curcumin NPs, decreased cell apoptosis, intracellular ROS levels, and the activity of Rac1. Besides, curcumin NPs suppressed the expression of gp91 ${ }^{\text {phox }}, \mathrm{p} 22^{\text {phox }}, \mathrm{p} 47^{\text {phox }}$, and $\mathrm{p} 67^{\text {phox }}$, which were induced by palmitate. Curcumin NPs significantly increased Bcl-2/Bax ratio, glucose-regulated protein 78, and C/EBP homologous protein expression in cardiomyocytes. Administration of curcumin NPs also inhibited apoptosis, decreased ROS generation and MDA content, increased SOD activity, and attenuated NADPH oxidase isoforms in cardiomyocytes. It was concluded that the endoplasmic reticulum stress-related signaling pathway probably mediated NADPH-induced oxidative stress inhibition. Therefore, curcumin NPs were suggested as possible drug formulations to improve lipid toxicityinduced myocardial injury. ${ }^{108,109}$ These effects might be implicated in regulating the expression of specific proteins and activation of the adenosine monophosphateactivated protein kinase signaling pathway. ${ }^{110}$ The effect of curcumin-loaded magnetic hydrogel nanocomposite (Cur-NIPAAM-MAA-NP) was also investigated against doxorubicin-induced cardiac toxicity in rats. Cardioprotective activity of Cur-NIPAAM-MAA-NP was approved by decreasing the atrial natriuretic peptide, 
B-type natriuretic peptide, and $\beta$-myosin heavy-chain gene expression as heart failure markers. ${ }^{111}$ It was also shown that the administration of curcumin-loaded lipid nanoemulsions $(\mathrm{CmLN})$, conjugated with a nano-arginine peptide (R9CmLN), had low hemolytic activity and low cytotoxic effect on human endothelial cells. It has recently been reported that PLGA-curcumin NPs effectively improved cardiovascular responses by reducing liver fat deposition and improving oral bioavailability of curcumin. ${ }^{112}$ In another study, curcumin NPs prevented the CK-MB leakage from cardiomyocytes in ISO-induced myocardial infarction in rats. The serum levels of IL-6, TNF- $\alpha$, MCP- 1 , IL- $1 \alpha$, and IL- $1 \beta$ did not increase after the induction of myocardial infarction. ${ }^{98}$ Administration of curcumin capped gold loaded poly (lactic-coglycolic acid) nanoparticles (CAu-PLGA Nps) inhibited cardiac hypertrophy via increasing solubility, bioavailability, and absorption, improving resistance to enzymatic degradation and drug delivery efficiency in a rat model. CAuPLGA Nps also increased survival rate, preserved myocardial function, and protected animals against cardiac toxicity and heart failure through their antiapoptotic, antioxidant, and anti-inflammatory properties. $^{113}$ Together, nano curcumin is a potent natural product formulation for treating a wide range of CVDs such as atherosclerosis, hypertension, myocardial infarction, diabetes, cardiac hypertrophy, and cardiomyopathy.

\section{Ginsenoside $\operatorname{Rg} 3$}

Ginsenoside Rg3 (Rg3), an active constituent of Panax ginseng, possesses anti-inflammatory, immunomodulatory, antioxidant, and anti-aging activities in different diseases. ${ }^{114-116} \mathrm{Rg} 3$ loaded in Pluronic F127 micelles (P-Rg3) effectively reduced doxorubicin-induced mortality, preserved the peak aortic blood velocity, and decreased the levels of atrial natriuretic peptide and B-type natriuretic peptide in $\mathrm{C} 57 / \mathrm{BL}$ mice. ${ }^{115} \mathrm{P}-\mathrm{Rg} 3$ significantly reduced the myocardial levels of LDH, CK, and CK-MB, thereby preserving cardiac membrane integrity compared to those in the doxorubicin group. P-Rg3 decreased apoptosis; suppressed the mRNA expression of Bax and increased Bcl-2; decreased caspase 3 and caspase 9 proteins expressions; alleviated mitochondrial swelling and crista reduction, and maintained mitochondrial arrays; decreased the levels of ROS and calcium overload; increased ATP content and reduced mtDNA copy number compared with those in the doxorubicin group. P-Rg3 was more effective than $\mathrm{Rg} 3$ at protecting the heart against doxorubicin-induced cardiotoxicity and prevented depolarization of the mitochondrial membrane in $\mathrm{H} 9 \mathrm{C} 2$ cells. The basal respiration, mitochondrial maximal respiration capacity, ATP production, and mitochondrial spare respiratory capacity were also markedly increased in P-Rg3-treated cells. This study indicated that co-administration of the polymeric micellar encapsulated natural products with chemotherapeutic agents increased their efficacy, decreased their toxicity, and was more effective than drug administration alone. ${ }^{115}$

\section{Panax notoginsenoside}

Panax notoginsenoside (PNS) is the primary active component of $P$. notoginseng. ${ }^{117}$ PNS is poorly absorbed after oral administration. ${ }^{118}$ Combination of PNS with a liposomal system [encapsulation of methyl ether poly (ethylene glycol)-poly(lactide-co-glycolide) (mPEGPLGA)-based NPs] enhanced the entrapment efficiency. It postponed releasing the significant components of PNS, including ginsenoside R1, ginsenoside Rb1, ginsenoside Rg1, and ginsenoside Rd. Treatment with PNS-coreshell hybrid liposomal vesicles (HLV) significantly decreased the serum levels of $\mathrm{LDH}, \mathrm{MDA}, \mathrm{H} 2 \mathrm{O} 2$, and increased SOD pituitrin-induced myocardial ischemia in rats versus the control group. In other words, PNS-HLV decreased infarction volume and improved biochemical parameters by improving its physicochemical properties. ${ }^{119}$ Salvianolic acid B (Sal B), isolated from the roots of Salvia miltiorrhiza, has been reported to protect the cardiovascular system through mechanisms mentioned previously by Deng et al 2015. ${ }^{120}$ A lipidpolymer hybrid NPs (LPNs) system was designed to assess the effect of SalB and PNS co-delivery on acute myocardial ischemia. ${ }^{121}$ The modified LPNs were stable in serum and prolonged the plasma circulation time. Combinational therapy virtually reduced the infarct size due to sustained release of drugs from the carriers, providing lasting antiapoptotic effects for up to $72 \mathrm{~h}$. In another study, the arginyl-glycyl-aspartic acid (RGD) peptide ligand was used to promote the myocardial infarction zone. RGDSal B and PNS-loaded system were stable and could enhance the in vivo therapeutic efficacy of both drugs and were not toxic against H9c2 cardiomyocytes. ${ }^{122}$

\section{Berberine}

Berberine, derived from Berberis spp., is a small fluorescent isoquinoline quaternary alkaloid. Berberine reduces triglycerides levels and systolic blood pressure. ${ }^{123,124}$ 
Despite potent anti-inflammatory, antioxidative, and cardioprotective activities of berberine, its application is limited due to low solubility in aqueous buffers, short half-life in blood circulation, and low absorption rate in the intestine. $^{31,125,126}$ In a mouse model of myocardial infarction, liposomal encapsulation of berberine improved its solubility, reduced adverse cardiac remodeling, and preserved left ventricular ejection. Furthermore, berberine encapsulation into long-circulating liposomes enhanced the accumulation of the compound in infarcted heart tissue and improved its local delivery and treatment efficacy. ${ }^{31}$

\section{Naringenin}

Naringenin is a flavanone existing in vegetables and citrus fruits such as orange and grapefruit. Its antioxidant, antiinflammatory, anti-hyperglycemic, and anti-mutagenic activities have been reported previously. ${ }^{32,127,128}$ Several strategies have been used to improve the pharmacokinetics of naringenin, including a combination of naringenin with cyclodextrin or liposome and incorporating this compound into chitosan core-shell NPs coated with alginate. ${ }^{129,130}$ Given the anti-inflammatory effects of naringenin and hesperetin, they are incorporated into PEGylated lipid nanoemulsions coupled with a vascular cell adhesion molecule 1 recognizing peptide to enhance their efficacies and to reduce endothelial cell inflammation. This combination inhibited adhesion and transmigration of monocyte to or through endothelial cells, reduced nuclear translocation of nuclear factor kappa B (NF- $\mathrm{B})$, produced MCP1, and ultimately reduced endothelium inflammation. ${ }^{131}$

\section{Tilianin}

Tilianin, a natural flavonoid compound extracted from Dracocephalum moldavica, has been used to treat cardiovascular conditions such as coronary heart disease, hypertension, atherosclerosis, and myocardial ischemia. ${ }^{33,132,133}$ An amphiphilic block polymer [(propylene sulfide)-copoly(ethylene glycol) (PEG-PPS)], has been designed to encapsulate tilianin. PEG-PPS could scavenge ROS due to sulfur atoms in its PPS block. ${ }^{134,135}$ The pharmacological effect of tilianin-loaded micelles (TLMs) on hypoxiareoxygenation $(\mathrm{H} / \mathrm{R})$ induced $\mathrm{H} 9 \mathrm{c} 2$ cardiomyocytes was investigated in a study. Upon the addition of some oxidants, tilianin was released from TLMs in vitro. Pretreatment of H/R- induced H9c2 cardiomyocytes with TLMs, reduced the LDH levels, preserved the ROS production, increased cell viability, and significantly reduced the MDA level in the cardiomyocytes. Toll-like receptor 4 and NF- $\kappa \mathrm{B}$ p65 protein expressions were also reduced according to the Western blot analysis. Despite the presence of relatively low drug loading capacity and cytotoxicity of high concentrations of polymer, TLMs could reduce the contents of IL- 1 and TNF- $\alpha$ and decreased the apoptosis rate of $\mathrm{H} 9 \mathrm{c} 2$ cardiomyocytes versus $H / R$ condition. $^{134}$

\section{Puerarin}

Puerarin (PUE), a primary active ingredient derived from Radix puerariae, acts as an antioxidant and has been widely used to improve CVDs. ${ }^{136-138}$ 1,2-Distearoyl-snglycero-3-phosphoethanolamine-N-[methoxy(polyethylene glycol)-2000] (PEG-PE) micelles were used to fabricate PUE-loaded PEG-PE (PUE@PEGPE) micelles and were assessed against ISO-induced apoptosis H9c2 cells. These micelles improved the bioavailability of PUE and extended its circulation time. PUE@PEG-PE pretreatment reversed the adverse effects of ISO, increased Bcl-2 expression while alleviating the caspase 3 activity and Bax expression in $\mathrm{H} 9 \mathrm{c} 2$ cells. PEG-PE micelles enhanced the protective effects of PUE against ISO-induced apoptosis in $\mathrm{H} 9 \mathrm{c} 2$ cells, also extended the drug delivery to $\mathrm{H} 9 \mathrm{c} 2$ cells. ${ }^{139}$ Consistent with this report, Li et al synthesized a PEG-PE copolymer containing a single terminal lipophilic triphenylphosphonium (TPP) cation to enhance the delivery efficacy of a mitochondrial targeting ligand. This copolymer was incorporated into PEG-PE to facilitate the penetration of NPs through the mitochondrial membrane. Administration of PUE-loaded TPP/PEG-PE (PUE@TPP/PEG-PE) micelles enhanced the antiapoptosis effect of PUE in ISO-induced H9c2 Cells, which was associated with higher delivery of PUE into the mitochondria. ${ }^{140}$ PUE@TPP/PEG-PE micelles enhanced the intracellular uptake of the desired drug in the ischemic zone. The system reduced the ROS level, Bax expression, and caspase-3 activity while increasing the Bcl-2 expression. Overall, PUE@TPP/PEG-PE micelles were suggested as a potent nanocarrier system to treat acute myocardial infarction. RGD peptide is another targeting moiety used for the targeted delivery of NPs loaded with therapeutics. ${ }^{141} \mathrm{Yu}$ et al reported intra-myocardial injections of RGD modified alginate, thereby enhancing angiogenesis. ${ }^{142}$ Considering the adverse effects of direct myocardial injection, such as invasive, volume-limitation, and sometimes causing further injury to the myocardium, Dong et al designed a novel RGD/PEGylated solid lipid NPs loaded with PUE (RGD/PEG-PUE-SLN) to deliver 
more drugs to the infarct zone. RGD/PEG-PUE-SLN was a favorable carrier for cardioprotective drug delivery in myocardial infarction treatment. ${ }^{143,144}$

\section{Quercetin}

Quercetin, a flavonoid isolated from various citrus fruits, tea, onions, and apples, exerts significant antioxidant, antiinflammatory, and antihypertensive activities. ${ }^{36,145,146}$ Quercetin-loaded phosphatidylcholine liposomes (PCLs) found protective against myocardial injuries induced by peroxynitrite by directly acting as both the scavenger and decomposer of endogenously formed peroxynitrite ions and thereby could restore the normal myocardial contractility in both anesthetized animals and isolated tissues. ${ }^{147}$ In another study, polymeric micelles loaded with a combination of resveratrol and quercetin were used to assess their cardioprotective actions against doxorubicininduced cardiotoxicity. This combination was effective in attenuating the cardiotoxicity in both in vivo and in vitro experiments. ${ }^{148}$ Besides, Giannoulia et al fabricated a quercetin-loaded polymeric PLGA NPs by electrohydrodynamic atomization process to improve its drawbacks and prevent atherosclerosis. Quercetin demonstrated excellent potential for preventing atherosclerosis and other CVDs, attributed to its biphasic release (24 hours and 59 days, respectively) from NPs. ${ }^{22}$ It is also reported that the delivery of quercetin-loaded PLGA NPs into H9c2 cells led to the preservation of mitochondrial function and ATP synthesis in hypoxia-reoxygenation conditions, which was attributed to suppression of oxidative stress. ${ }^{149}$ Wang et al built PLGA-covered polymeric superparamagnetic nanosilica@PLGA (SiN@PLGA) loaded with quercetin to improve its low water solubility and control the medication discharge from the nanocarriers. The manufactured nanocomposite guaranteed secure and controlled release of the quercetin, permitting cell enlistment, attachment, expansion, and articulation of heart proteins in local myocardium. ${ }^{150}$

\section{Baicalin}

Baicalin, one of the significant bioactive flavone glucuronides derived from Scutellaria Radix, was shown to exert anti-inflammatory and antioxidant activities. Baicalin was also shown to suppress the expression of many inflammatory chemokines and cytokines. ${ }^{151}$ It has been used to alleviate diabetes and CVDs. ${ }^{23,152}$ Various nanosized formulations have been used to overcome low hydrophilicity, short half-life, and poor absorption of baicalin following oral administration. ${ }^{153}$ Baicalin-loaded PEGylated nanostructured lipid carriers (BN-PEG-NLC) prolonged its plasma circulation time, enhanced its delivery to the ischemic area of the heart, and reduced the infarct size in the acute myocardial infarction model. PEG-NLC was suggested as an effective biocompatible carrier for hearttargeted drug delivery of baicalin.

\section{Resveratrol}

Resveratrol is a polyphenol commonly found in berries, grapes, and peanuts with a broad spectrum of pharmacological activities such as cardioprotective, anticancer, antioxidant, antiangiogenic, and immunomodulatory. ${ }^{154,155}$ Shahraki et al synthesized resveratrol-loaded nanocapsules and assessed the effect of this nanoformulation in mice with fat diet-induced metabolic syndrome. Synthesis of resveratrol nanocapsule has also been reported using polycaprolactone, a biodegradable polymer. Administration of resveratrol nanocapsules significantly reduced both the systolic and diastolic blood pressures and alleviated insulin resistance in mice due to reduced whole-body fat. ${ }^{156}$ Since both curcumin and resveratrol can act as chemosensitizers and antioxidant agents, Carlson et al used their polymeric micellar co-delivery to lessen doxorubicininduced cardiotoxicity. Encapsulation of curcumin and resveratrol in F127 micelles increased their aqueous solubility; resveratrol by 29.6 -fold, and curcumin by 1617 fold. Improved cardioprotection in $\mathrm{H} 9 \mathrm{C} 2$ cells, either when curcumin and resveratrol were used as free drugs or when they were loaded in micelles with doxorubicin, was implicated in ROS scavenging and apoptosis prevention. ${ }^{157}$ In another study, administration of resveratrol-loaded solid lipid NPs significantly increased the heart rate, ejection fractions, and fractional shortening in doxorubicin-induced cardiotoxicity mice. The myocardial fibers were also arranged regularly, and a few vacuole degenerations were seen in the myocardial cells. ${ }^{158}$

\section{Breviscapine}

Breviscapine, a flavone glucuronide isolated from a traditional Chinese herb, Erigeron breviscapus, is commonly used to treat coronary heart disease, angina pectoris, and cerebral infarction. It was also shown favorable for CVDs by removing blood stasis and promoting blood circulation. ${ }^{159}$ Scutellarin, the primary active component of Breviscapine, has limitations such as poor chemical stability, low aqueous solubility, and short biological halflife. $^{160}$ A lipid emulsion formulation loaded with 
Breviscapine exhibited desirable sustained release. It was safe for intravenous administration while being chemically and physically stable for 6 months at room temperature. This formula also increased the amount and prolonged the retention time of Breviscapine in the heart, which would be beneficial in CVDs therapy. ${ }^{161}$

\section{Magnolol}

Magnolol (5,5'-diallyl-2,2'-dihydroxy biphenyl), a bioactive compound isolated from Magnolia Officinalis, has been used to inhibit cell growth, induce cell apoptosis, and treat various inflammatory diseases. ${ }^{162-166}$ It was evidenced that magnolol suppresses the expression of TNFinduced vascular cell adhesion molecule 1 (VCAM-1) in endothelial cells. ${ }^{167}$ It was stated that encapsulated magnolol in either 1,2-diacyl-sn-glycero-3-phosphocholine (EPC) liposome or 1,2-dipalmitoyl-sn-glycero-3-phosphocholine (DPPC) liposome inhibited the proliferation of vascular smooth muscle cells (VSMCs). The inhibitory effect of encapsulated magnolol was higher than the pure magnolol. Also, magnolol-EPC was more effective than DPPC liposome. ${ }^{168}$

HUVECs were used to investigate the antiinflammatory mechanisms of magnolol NPs. In vitro administration of magnolol NPs was shown to suppress the activity of TNF $\alpha$-induced VCAM-1 promoter. They attenuated TNF $\alpha$-induced VCAM-1 mRNA and protein expressions in endothelial cells, mediated by the protein kinase B (AKT), extracellular signal-regulated kinases (ERK), and NF- $\mathrm{KB}$ signaling pathways. Furthermore, in vivo administration of magnolol NPs, effectively suppressed TNF- $\alpha$-induced VCAM-1 expression on the aortic endothelium. Overall, magnolol NPs could be a potentially useful therapeutic nanoformulation to treat inflammatory diseases and atherosclerosis. ${ }^{169}$

\section{Epigallocatechin}

(-)-Epigallocatechin-3-gallate (EGCG) includes 25-55\% of the total catechins in green tea. ${ }^{170}$ It was demonstrated that EGCG prevented atherosclerosis formation by decreasing inflammatory responses and cholesterol accumulation in macrophages. ${ }^{171,172}$ Zhang et al developed EGCG-loaded NPs (Enano) using alpha-tocopherol acetate (as an antioxidant), kolliphor HS15 (a commonly used nonionic solubilizer), and phosphatidylcholine. Then, a ligand-Enano (L-Enano) was prepared via incorporating KOdiA-PC (a CD36-targeted ligand found on oxLDL) on the surface of Enano. The final product, CD36-targeted
L-Enano, significantly improved the stability of EGCG, exhibited a higher binding affinity for macrophages, enhanced the macrophage-EGCG content, and decreased the macrophage mRNA levels and protein secretion of MCP-1 in human monocytic THP-1 cells. CD36-targeted NPs were proposed as carriers for targeted delivery of antiatherogenic compounds to intimal macrophages to prevent or mediate atherosclerosis. ${ }^{173}$ Chitosan-coated EGCG exhibited similar results as encapsulated nanostructured lipid carriers. ${ }^{174}$

\section{Tanshinone}

Tanshinone IIA (TA), a lipophilic pharmacologically active compound derived from the Salvia miltiorrhiza Bunge rhizome, is of interest for CVDs therapy. TA exhibited significant therapeutic effects, including vasodilatory potential, scavenger activity, the preventive effect on endothelial dysfunction, retarding effect on macrophage-derived foam cells formation, and the inhibitory effect on the proliferation and migration of vascular smooth muscle cells. ${ }^{175,176}$ Low solubility, short half-life, poor bioavailability, and low oral bioavailability are the major drawbacks of this compound. ${ }^{177}$ To improve the clinical delivery of TA, several methodologies were developed. For example, both discoidal and spherical recombinant HDL (d-rHDL and s-rHDL) loaded with TA have a high affinity towards atherosclerotic lesions than normal vessel walls. Moreover, based on the pharmacodynamic studies, both TAd-rHDL and TA-s-rHDL presented higher antiatherogenic activities than conventional TA nanostructured lipid carriers (TA-NLC), TA liposomes (TA-L), and commercially available preparation sulfotanshinone sodium injection. TA-s-rHDL found more potent than TA-d-rHDL. ${ }^{178}$ In another study, lipid-polymeric nanocarriers of tanshinone IIA, TA/LPNs exhibited superior mitochondrial-targeted efficacy in compatibility and therapeutic features than free TA and TA/NPs. ${ }^{179}$ Furthermore, it was demonstrated that monomethoxypoly (ethylene glycol)-poly (lactic acid)-D- $\alpha$-tocopheryl polyethylene glycol 1000 succinate (mPEG-PLA-TPGS) nanoparticle loaded with tanshinone IIA limited the infarct expansion and reduced adverse cardiac remodeling and dysfunction. ${ }^{180}$ Collectively, TA-s-rHDL, TPP-TPGS/TA/LPNs, and TA/mPEG-PLA-TPGS nanoparticles could be exploited as a novel approach to improve atherosclerotic lesions and myocardial IR injury in patients with MI. 


\section{Conclusion}

Given the prevalence of CVDs, efficient strategies seem necessary for either prevention or treatment approaches. Data from past decades signified the therapeutic potential of many herbal and natural compounds against CVDs, with lower side effects than chemical drugs. Herbal extracts' antioxidant and anti-inflammatory properties are the critical characteristics that make them favorable candidates for CVDs treatment. Efficient and controlled delivery of drugs into the target sites of action and improving their physicochemical features are the primary purposes of natural-based nanoformulation. Therefore, nano carrierbased drug delivery systems have been applied to sustain and control drug release, avoid drug degradation, improve bioavailability, and prolong drug residence time in the systemic circulation. The current review provides an overview of the probable therapeutic advantages of nanophytomedicine for CVDs treatment, along with recent advancements in this field. As presented, the efficacy of nanoformulations of herbal extracts and their bioactive phytochemicals is significantly higher than conventional formulations. The preparation methods and the type of nanoformulation affect their chemical characteristics and functionalities. To date, many nanoformulations have been applied and investigated in both in vitro and in vivo conditions against CVDs. However, their applications in clinical states are still on the way, and it is necessary to translate the outputs of these studies into clinical trials. According to the literature, ISO-induced cardiac hypertrophy, myocardial infarction, doxorubicin-induced cardiotoxicity, hypertension, atherosclerosis, and diabetic cardiomyopathy were the most common methodologies were used to assess nanophytomedicines. Curcumin, quercetin, and resveratrol were the most applied natural products, respectively.

On the other hand, liposome nanocarriers were the most used technique for nanoformulation. Antihypercholesterolemic and antiatherosclerotic effects of curcumin, besides its cardioprotective properties, propose it as the most interesting cardioprotective compound. In vitro and in vivo experiments have revealed that combination therapy (eg, atorvastatin and curcumin; resveratrol and quercetin; curcumin and nisin) is more efficient due to their synergistic effects. Fabrication of NPs or nanocarriers by techniques such as PEGylating solid lipid NPs loaded with therapeutic agents or coating them with superparamagnetic nano-silica improves the drug penetration into the target tissue, thereby enhancing its therapeutic efficacy.

\section{Prospects}

Although numerous cardioprotective drugs have been utilized to prevent and treat CVDs, researchers have focused on herbal or natural-based nanoformulations due to their higher solubility, bioavailability, and efficiency, lower side effects, and having the potential to be more specific by targeted delivery to the cardiovascular tissue. Encapsulation of natural- or herbal-based medications in NPs enhances their antioxidant and anti-inflammatory activities, increases their bioavailability, and improves their efficiency. Innovative targeted nanophytomedicines are recommended as valuable alternatives for the management of CVDs. Although several natural-based nanoformulations have been tested in both in vitro and in vivo, clinical trials are warranted. The safety profiles (eg, allergic responses, DNA damage, excitotoxicity, and neuroinflammation) of nanophytomedicines have to be assessed. Overall, therapeutic applications of nanophytomedicines in CVDs are still in their initial phases.

\section{Acknowledgments}

This work was supported by Kermanshah University of Medical Sciences (code number 990826), directed to Mahvash Hesari.

\section{Author Contributions}

All authors made a significant contribution to the work reported, whether that is in the conception, study design, execution, acquisition of data, analysis and interpretation, or in all these areas; took part in drafting, revising or critically reviewing the article; gave final approval of the version to be published; have agreed on the journal to which the article has been submitted; and agree to be accountable for all aspects of the work.

\section{Disclosure}

The authors have no conflicts of interest to declare for this work.

\section{References}

1. World Health Organization. World Health Statistics 2016: Monitoring Health for the SDGs Sustainable Development Goals. World Health Organization; 2016.

2. Dimmeler S. Cardiovascular disease review series. EMBO Mol Med. 2011;3(12):697. doi:10.1002/emmm.201100182 
3. Stewart J, Manmathan G, Wilkinson P. Primary prevention of cardiovascular disease: a review of contemporary guidance and literature. JRSM Cardiovasc Dis. 2017;6:2048004016687211. doi: $10.1177 / 2048004016687211$

4. Yusuf S, Sleight P, Pogue J, Bosch J, Davies R, Dagenais G; Heart Outcomes Prevention Evaluation Study Investigators. Effects of an angiotensin-converting-enzyme inhibitor, ramipril, on cardiovascular events in high-risk patients. $N$ Engl $J$ Med. 2000;342:1376. Massachusetts Medical Society. doi:10.1056/ NEJM200005043421819

5. Martín Giménez VM, Kassuha DE, Manucha W. Nanomedicine applied to cardiovascular diseases: latest developments. Ther $A d v$ Cardiovasc Dis. 2017;11(4):133-142. doi:10.1177/17539447176 92293

6. Radomska A, Leszczyszyn J, Radomski MW. The nanopharmacology and nanotoxicology of nanomaterials: new opportunities and challenges. Adv Clin Exp Med. 2016;25(1):151-162. doi:10. 17219/acem/60879

7. Siddiqui A, Iram F, Siddiqui S, Sahu K. Role of natural products in drug discovery process. Int J Drug Dev Res. 2014;6 (2):172-204.

8. Yuan H, Ma Q, Ye L, Piao G. The traditional medicine and modern medicine from natural products. Molecules. 2016;21 (5):559.

9. Clark AM. Natural products as a resource for new drugs. Pharm Res. 1996;13(8):1133-1144. doi:10.1023/a:1016091631721

10. Sorokina M, Steinbeck C. Review on natural products databases: where to find data in 2020. J Cheminform. 2020;12(1):1-51. doi:10.1186/s13321-020-00424-9

11. Mushtaq S, Abbasi BH, Uzair B, Abbasi R. Natural products as reservoirs of novel therapeutic agents. EXCLI J. 2018;17:420.

12. Rahimi HR, Nedaeinia R, Sepehri Shamloo A, Nikdoust S, Kazemi Oskuee R. Novel delivery system for natural products: nano-curcumin formulations. Avicenna J Phytomed. 2016;6 (4):383-398.

13. Taghipour YD, Hajialyani M, Naseri R, et al. Nanoformulations of natural products for management of metabolic syndrome. Int J Nanomedicine. 2019;14:5303-5321. doi:10.2147/IJN.S21 3831

14. Moradi SZ, Momtaz S, Bayrami Z, Farzaei MH, Abdollahi M. Nanoformulations of herbal extracts in treatment of neurodegenerative disorders. Front Bioeng Biotechnol. 2020;8. doi:10.3389/ fbioe. 2020.00238

15. Rosler A, Vandermeulen GW, Klok HA. Advanced drug delivery devices via self-assembly of amphiphilic block copolymers. $A d v$ Drug Deliv Rev. 2001;53(1):95-108. doi:10.1016/s0169-409x(01) 00222-8

16. Karthikeyan A, Senthil N, Min T. Nanocurcumin: a promising candidate for therapeutic applications. Front Pharmacol. 2020;11. doi:10.3389/fphar.2020.00487

17. Houacine C, Singh KK. 10 Nano resveratrol: a promising future nanonutraceutical. NanoNutraceuticals. 2018.

18. Ahn K. The worldwide trend of using botanical drugs and strategies for developing global drugs. BMB Rep. 2017;50(3):111-116. doi:10.5483/bmbrep.2017.50.3.221

19. Dong TTX, Cui XM, Song ZH, et al. Chemical assessment of roots of panax notoginseng in China: regional and seasonal variations in its active constituents. J Agric Food Chem. 2003;51 (16):4617-4623. doi:10.1021/jf034229k

20. Rao PR, Viswanath RK. Cardioprotective activity of silymarin in ischemia-reperfusion-induced myocardial infarction in albino rats. Exp Clin Cardiol. 2007;12(4):179-187.

21. Yu B, Fang T-H, Lu G-H, Xu H-Q, Lu J-F. Beneficial effect of cyclovirobuxine $\mathrm{D}$ on heart failure rats following myocardial infarction. Fitoterapia. 2011;82(6):868-877. doi:10.1016/j.fitote. 2011.04.016
22. Giannouli M, Karagkiozaki V, Pappa F, Moutsios I, Gravalidis C, Logothetidis S. Fabrication of quercetin-loaded PLGA nanoparticles via electrohydrodynamic atomization for cardiovascular disease. Mater Today Proc. 2018;5(8):15998-16005. doi:10.10 16/j.matpr.2018.05.044

23. Dinda B, Dinda S, DasSharma S, Banik R, Chakraborty A, Dinda M. Therapeutic potentials of baicalin and its aglycone, baicalein against inflammatory disorders. Eur J Med Chem. 2017;131:68-80. doi:10.1016/j.ejmech.2017.03.004

24. Bremer AA. Resveratrol use in metabolic syndrome. Metab Syndr Relat Disord. 2014;12(10):493-495. doi:10.1089/met.2014.1505

25. Cook KM, Figg WD. Angiogenesis inhibitors: current strategies and future prospects. CA Cancer J Clin. 2010;60(4):222-243. doi:10.3322/caac. 20075

26. Sun G-B, Qin M, Ye J, et al. Inhibitory effects of myricitrin on oxidative stress-induced endothelial damage and early atherosclerosis in ApoE-/- mice. Toxicol Appl Pharmacol. 2013;271 (1):114-126. doi:10.1016/j.taap.2013.04.015

27. Hamza A, Amin A, Daoud S. The protective effect of a purified extract of Withania somnifera against doxorubicin-induced cardiac toxicity in rats. Cell Biol Toxicol. 2008;24(1):63-73. doi:10.1007/s10565-007-9016-Z

28. Zanwar AA, Hegde MV, Bodhankar SL. Cardioprotective activity of flax lignan concentrate extracted from seeds of Linum usitatissimum in isoprenalin induced myocardial necrosis in rats. Interdiscip Toxicol. 2011;4(2):90-97. doi:10.2478/v10102-0110016-8

29. Li X, Fang Q, Tian X, et al. Curcumin attenuates the development of thoracic aortic aneurysm by inhibiting VEGF expression and inflammation. Mol Med Rep. 2017;16(4):4455-4462. doi:10.38 92/mmr.2017.7169

30. Campbell MS, Fleenor BS. The emerging role of curcumin for improving vascular dysfunction: a review. Crit Rev Food Sci Nutr. 2018;58(16):2790-2799. doi:10.1080/10408398.2017.1341 865

31. Allijn IE, Czarny BMS, Wang X, et al. Liposome encapsulated berberine treatment attenuates cardiac dysfunction after myocardial infarction. $J$ Control Release. 2017;247:127-133. doi:10.10 16/j.jconrel.2016.12.042

32. Cavia-Saiz M, Busto M, Pilar-Izquierdo M, Ortega Santamaría N, Perez-Mateos M, Muñiz P. Antioxidant properties, radical scavenging activity and biomolecule protection capacity of flavonoid naringenin and its glycoside naringin: a Comparative Study. J Sci Food Agric. 2010;90(7):12 38-1244. doi:10.1002/jsfa.3959

33. Hernandez-Abreu O, Torres-Piedra M, Garcia-Jimenez S, et al. Dose-dependent antihypertensive determination and toxicological studies of tilianin isolated from Agastache mexicana. J Ethnopharmacol. 2013;146(1):187-191. doi:10.1016/j.jep.2012. 12.029

34. Guo X, Cao W, Yao J, et al. Cardioprotective effects of tilianin in rat myocardial ischemia-reperfusion injury. Mol Med Rep. 2014;11. doi:10.3892/mmr.2014.2954

35. Stoll A, Seebeck E. Chemical investigations on alliin, the specific principle of garlic. Adv Enzymol Relat Subj Biochem. 1951; 11:377-400. doi:10.1002/9780470122563.ch8

36. Hashemzaei M, Delarami Far A, Yari A, et al. Anticancer and apoptosis-inducing effects of quercetin in vitro and in vivo. Oncol Rep. 2017;38(2):819-828. doi:10.3892/or.2017.5766

37. Pereira M, Siba IP, Chioca LR, et al. Myricitrin, a nitric oxide and protein kinase $\mathrm{C}$ inhibitor, exerts antipsychotic-like effects in animal models. Prog Neuropsychopharmacol Biol Psychiatry. 2011;35(7):1636-1644. doi:10.1016/j.pnpbp.2011.06.002

38. Patra JK, Das FL. Nano based drug delivery systems: recent developments and future prospects. $J$ Nanobiotechnology. 2018;16. doi:10.1186/s12951-018-0392-8 
39. Lombardo D, Kiselev MA, Caccamo MT. Smart nanoparticles for drug delivery application: development of versatile nanocarrier platforms in biotechnology and nanomedicine. J Nanomater. 2019;2019:1-26. doi:10.1155/2019/3702518

40. Gao W, Zhang L. Coating nanoparticles with cell membranes for targeted drug delivery. J Drug Target. 2015;23(7-8):619-626. doi:10.3109/1061186X.2015.1052074

41. Kayal S, Ramanujan RV. Doxorubicin loaded PVA coated iron oxide nanoparticles for targeted drug delivery. Mater Sci Eng C. 2010;30(3):484-490. doi:10.1016/j.msec.2010.01.006

42. Chomoucka J, Drbohlavova J, Huska D, Adam V, Kizek R, Hubalek J. Magnetic nanoparticles and targeted drug delivering. Pharmacol Res. 2010;62(2):144-149. doi:10.1016/j.phrs.2010. 01.014

43. Lundy DJ, Chen K-H, Toh EK-W, Hsieh PC-H. Distribution of systemically administered nanoparticles reveals a size-dependent effect immediately following cardiac ischaemia-reperfusion injury. Sci Rep. 2016;6:25613. doi:10.1038/srep25613

44. Kumar VV, Chandrasekar D, Ramakrishna S, Kishan V, Rao YM, Diwan PV. Development and evaluation of nitrendipine loaded solid lipid nanoparticles: influence of wax and glyceride lipids on plasma pharmacokinetics. Int J Pharm. 2007;335(1-2):167-175. doi:10.1016/j.ijpharm.2006.11.004

45. Broz P, Ben-Haim N, Grzelakowski M, Marsch S, Meier W, Hunziker P. Inhibition of macrophage phagocytotic activity by a receptor-targeted polymer vesicle-based drug delivery formulation of pravastatin. $J$ Cardiovasc Pharmacol. 2008;51(3): 246-252. doi:10.1097/FJC.0b013e3181624aed

46. La Francesca S. Nanotechnology and stem cell therapy for cardiovascular diseases: potential applications. Methodist Debakey Cardiovasc J. 2012;8(1):28-35. doi:10.14797/mdcj8-1-28

47. Binsalamah ZM, Paul A, Khan AA, Prakash S, Shum-Tim D. Intramyocardial sustained delivery of placental growth factor using nanoparticles as a vehicle for delivery in the rat infarct model. Int J Nanomedicine. 2011;6:2667-2678. doi:10.2147/IJN S25175

48. Myerson J, He L, Lanza G, Tollefsen D, Wickline S. Thrombininhibiting perfluorocarbon nanoparticles provide a novel strategy for the treatment and magnetic resonance imaging of acute thrombosis. J Thromb Haemost. 2011;9(7):1292-1300. doi:10. 1111/j.1538-7836.2011.04339.x

49. Waltenberger B, Mocan A, Šmejkal K, Heiss EH, Atanasov AG. Natural products to counteract the epidemic of cardiovascular and metabolic disorders. Molecules. 2016;21(6):807.

50. Sobhani Z, Reza Nami S, Ahmad Emami S, Sahebkar A, Javadi B. Medicinal plants targeting cardiovascular diseases in view of Avicenna. Curr Pharm Des. 2017;23(17):2428-2443.

51. Petrovska BB. Historical review of medicinal plants' usage. Pharmacogn Rev. 2012;6(11):1.

52. Lin MC, Nahin R, Gershwin ME, Longhurst JC, Wu KK. State of complementary and alternative medicine in cardiovascular, lung, and blood research: executive summary of a workshop. Circulation. 2001;103(16):2038-2041.

53. Jérôme C, Lecomte P. Recent advances in the synthesis of aliphatic polyesters by ring-opening polymerization. Adv Drug Deliv Rev. 2008;60(9):1056-1076.

54. Koehn FE, Carter GT. The evolving role of natural products in drug discovery. Nat Rev Drug Discov. 2005;4(3):206-220.

55. Du Y, Liu P, Yuan Z, et al. Simultaneous qualitative and quantitative analysis of 28 components in Isodon rubescens by HPLCESI-MS/MS. J Sep Sci. 2010;33(4-5):545-557.

56. Kariyazono $H$, Nakamura $K$, Shinkawa $T$, Yamaguchi $T$, Sakata R, Yamada K. Inhibition of platelet aggregation and the release of P-selectin from platelets by cilostazol. Thromb Res. 2001;101(6):445-453.
57. Sanz MJ, Cortijo J, Morcillo EJ. PDE4 inhibitors as new anti-inflammatory drugs: effects on cell trafficking and cell adhesion molecules expression. Pharmacol Ther. 2005;106(3):269-297.

58. Wang Y, Tang J, Zhu H, et al. Aqueous extract of Rabdosia rubescens leaves: forming nanoparticles, targeting P-selectin, and inhibiting thrombosis. Int J Nanomedicine. 2015;10:6905.

59. Atale N, Jaiswal A, Chhabra A, et al. Phytochemical and antioxidant screening of Syzygium cumini seed extracts: a comparative study. J Pharm Res. 2011;4(12):4530-4532.

60. Neha A, Vibha R. GC-MS analysis of bioactive components in the ethanolic and methanolic extract of Syzygium cumini. Int J Pharma Bio Sci. 2013;4(4).

61. Atale N, Chakraborty M, Mohanty S, et al. Cardioprotective role of syzygium cumini against glucose-induced oxidative stress in H9C2 cardiac myocytes. Cardiovasc Toxicol. 2013;13. doi:10.1007/s12012-013-9207-1

62. Atale N, Gupta K, Rani V. Protective effect of Syzygium cumini against pesticide-induced cardiotoxicity. Environ Sci Pollut Res. 2014;21(13):7956-7972.

63. Atale N, Saxena S, Nirmala JG, Narendhirakannan RT, Mohanty S, Rani V. Synthesis and characterization of Sygyzium cumini nanoparticles for its protective potential in high glucose-induced cardiac stress: a green approach. Appl Biochem Biotechnol. 2017;181(3):1140-1154.

64. Ferretti G, Bacchetti T, Belleggia A, Neri D. Cherry antioxidants: from farm to table. Molecules. 2010;15(10):6993-7005.

65. Scalbert A, Manach C, Morand C, Rémésy C, Jiménez L. Dietary polyphenols and the prevention of diseases. Crit Rev Food Sci Nutr. 2005;45(4):287-306.

66. Beconcini D, Fabiano A, Zambito Y, et al. Chitosan-based nanoparticles containing cherry extract from Prunus avium L. to improve the resistance of endothelial cells to oxidative stress. Nutrients. 2018;10(11). doi:10.3390/nu10111598

67. Beconcini D, Fabiano A, Di Stefano R, et al. Cherry extract from Prunus avium L. to improve the resistance of endothelial cells to oxidative stress: mucoadhesive chitosan vs. poly (lactic-coglycolic acid) nanoparticles. Int J Mol Sci. 2019;20(7):1759.

68. Beconcini D, Felice F, Zambito Y, et al. Anti-inflammatory effect of cherry extract loaded in polymeric nanoparticles: relevance of particle internalization in endothelial cells. Pharmaceutics. 2019;11(10):500.

69. Najafi M, Ghasemian E, Fathiazad F, Garjani A. Effects of total extract of dracocephalum moldavica on ischemia/reperfusion induced arrhythmias and infarct size in the isolated rat heart. Iran J Basic Med Sci. 2009;11(4):229-235. doi:10.22038/ ijbms.2009.5186

70. Yang LN, Xing JG, He CH, Yang PM. Chemical constituents of Dracocephalum moldavica L. and their pharmacological activities. World Clin Drugs. 2013;34(4):226-231.

71. Jiang J, Yuan X, Wang T, et al. Antioxidative and cardioprotective effects of total flavonoids extracted from Dracocephalum moldavica $\mathrm{L}$. against acute ischemia/reperfusion-induced myocardial injury in isolated rat heart. Cardiovasc Toxicol. 2014;14 (1):74-82.

72. Tan M, He C, Jiang W, et al. Development of solid lipid nanoparticles containing total flavonoid extract from Dracocephalum moldavica L. and their therapeutic effect against myocardial ischemia-reperfusion injury in rats. Int $J$ Nanomedicine. 2017;12:3253.

73. Ghayur MN, Gilani AH, Rasheed H, et al. Cardiovascular and airway relaxant activities of peony root extract. Can J Physiol Pharmacol. 2008;86(11):793-803. doi:10.1139/Y08-084

74. Ibrar M, Khan MA, Nisar M, Khan M. Evaluation of Paeonia emodi for its cardioprotective potentials: an investigative study towards possible mechanism. J Ethnopharmacol. 2019;231: $57-65$. 
75. Ibrar M, Khan MA, Imran M. Evaluation of Paeonia emodi and its gold nanoparticles for cardioprotective and antihyperlipidemic potentials. J Photochem Photobiol B Biol. 2018;189:5-13.

76. Li -Y-Y, Feng J, Zhang X-L, Cui -Y-Y. Pine bark extracts: nutraceutical, pharmacological, and toxicological evaluation. J Pharmacol Exp Ther. 2015;353(1):9-16.

77. Park I-J, Cha S-Y, Kang M, et al. Effect of proanthocyanidin-rich extract from Pinus radiata bark on immune response of specific-pathogen-free white leghorn chickens. Poult Sci. 2011;90(5):977-982.

78. Sudjarwo S, Anwar C, Eraiko K, Koerniasari WG. Cardioprotective activity of Chitosan-Pinus merkusii extract nanoparticles against lead acetate induced cardiac cell damage in rat. Rasayan J Chem. 2019;12:184-191. doi:10.31788/ RJC.2019.1215049

79. Ali BH, Blunden G, Tanira MO, Nemmar A. Some phytochemical, pharmacological and toxicological properties of ginger (Zingiber officinale Roscoe): a review of recent research. Food Chem Toxicol. 2008;46(2):409-420. doi:10.1016/J.FCT.2007. 09.085

80. Verma SK, Singh M, Jain P, Bordia A. Protective Effect of Ginger, Zingiber Officinale Rosc on Experimental Atherosclerosis in Rabbits. 2004.

81. Young H-Y, Liao J-C, Chang Y-S, Luo Y-L, Lu M-C, Peng W-H. Synergistic effect of ginger and nifedipine on human platelet aggregation: a study in hypertensive patients and normal volunteers. Am J Chin Med. 2006;34(04):545-551.

82. Ghayur MN, Gilani AH, Afridi MB, Houghton PJ. Cardiovascular effects of ginger aqueous extract and its phenolic constituents are mediated through multiple pathways. Vascul Pharmacol. 2005;43(4):234-241.

83. Al-Amin ZM, Thomson M, Al-Qattan KK, Peltonen-Shalaby R, Ali M. Anti-diabetic and hypolipidaemic properties of ginger (Zingiber officinale) in streptozotocin-induced diabetic rats. $\mathrm{Br}$ J Nutr. 2006;96(4):660-666.

84. Borcan F, Chirita-Emandi A, Andreescu NI, et al. Synthesis and preliminary characterization of polyurethane nanoparticles with ginger extract as a possible cardiovascular protector. Int J Nanomedicine. 2019;14:3691.

85. Atanasov AG, Waltenberger B, Pferschy-Wenzig E-M, et al. Discovery and resupply of pharmacologically active plant-derived natural products: a review. Biotechnol Adv. 2015;33(8):1582-1614.

86. Hosseinzadeh L, Behravan J, Mosaffa F, Bahrami G, Bahrami AR, Karimi G. Effect of curcumin on doxorubicin-induced cytotoxicity in $\mathrm{H} 9 \mathrm{c} 2$ cardiomyoblast cells. Iran J Basic Med Sci. 2011;14(1):49-56.

87. Kocaadam B, Şanlier N. Curcumin, an active component of turmeric (Curcuma longa), and its effects on health. Crit Rev Food Sci Nutr. 2017;57(13):2889-2895.

88. He Y, Yue Y, Zheng X, Zhang K, Chen S, Du Z. Curcumin, inflammation, and chronic diseases: how are they linked? Molecules. 2015;20(5):9183-9213.

89. Anand P, Kunnumakkara AB, Newman RA, Aggarwal BB. Bioavailability of curcumin: problems and promises. $\mathrm{Mol}$ Pharm. 2007;4(6):807-818.

90. Rachmawati H, Soraya IS, Kurniati NF, Rahma A. In vitro study on antihypertensive and antihypercholesterolemic effects of a curcumin nanoemulsion. Sci Pharm. 2016;84(1):131-140.

91. Tong F, Chai R, Jiang H, Dong B. In vitro/vivo drug release and antidiabetic cardiomyopathy properties of curcumin/PBLG-PEGPBLG nanoparticles. Int J Nanomedicine. 2018;13:1945.

92. Boarescu P-M, Boarescu I, Bocșan IC, et al. Antioxidant and anti-inflammatory effects of curcumin nanoparticles on drug-induced acute myocardial infarction in diabetic rats. Antioxidants. 2019;8(10):504.
93. Hardy N, Viola HM, Johnstone VPA, et al. Nanoparticle-mediated dual delivery of an antioxidant and a peptide against the L-type $\mathrm{Ca} 2+$ channel enables simultaneous reduction of cardiac ischemia-reperfusion injury. ACS Nano. 2015;9(1):279-289.

94. Ray A, Rana S, Banerjee D, et al. Improved bioavailability of targeted curcumin delivery efficiently regressed cardiac hypertrophy by modulating apoptotic load within cardiac microenvironment. Toxicol Appl Pharmacol. 2016;290:54-65.

95. Rice KM, Manne NDPK, Kolli MB, et al. Curcumin nanoparticles attenuate cardiac remodeling due to pulmonary arterial hypertension. Artif Cells Nanomed Biotechnol. 2016;44 (8):1909-1916.

96. Boarescu P-M, Boarescu I, Bocșan IC, et al. Curcumin nanoparticles protect against isoproterenol induced myocardial infarction by alleviating myocardial tissue oxidative stress, electrocardiogram, and biological changes. Molecules. 2019;24(15):2802.

97. Ranjan AP, Mukerjee A, Helson L, Vishwanatha JK. Mitigating prolonged QT interval in cancer nanodrug development for accelerated clinical translation. J Nanobiotechnology. 2013;11(1):40.

98. Boarescu P-M, Chirilă I, Bulboacă AE, et al. Effects of curcumin nanoparticles in isoproterenol-induced myocardial infarction. Oxid Med Cell Longev. 2019;2019.

99. Taylor AJ, Kent SM, Flaherty PJ, Coyle LC, Markwood TT, Vernalis MN. ARBITER: arterial biology for the investigation of the treatment effects of reducing cholesterol: a randomized trial comparing the effects of atorvastatin and pravastatin on carotid intima medial thickness. Circulation. 2002;106 (16):2055-2060.

100. Aydin U, Ugurlucan M, Gungor F, et al. Effects of atorvastatin on vascular intimal hyperplasia: an experimental rodent model. Angiology. 2009;60(3):370-377. Sage Publications Sage CA: Los Angeles, CA. doi:10.1177/0003319708321102

101. Olszanecki R, Jawień J, Gajda M, et al. Effect of curcumin on atherosclerosis in apoE/LDLR-double knockout mice. J Physiol Pharmacol. 2005;56(4):627-635.

102. Li X, Xiao H, Lin C, et al. Synergistic effects of liposomes encapsulating atorvastatin calcium and curcumin and targeting dysfunctional endothelial cells in reducing atherosclerosis. Int J Nanomedicine. 2019;14:649. doi:10.21 47/IJN.S189819

103. Abdel-Mageid AD, Abou-Salem MES, Salaam NMHA, ElGarhy HAS. The potential effect of garlic extract and curcumin nanoparticles against complication accompanied with experimentally induced diabetes in rats. Phytomedicine. 2018;43:126-134. doi:10.1016/j.phymed.2018.04.039

104. Joo NE, Ritchie K, Kamarajan P, Miao D, Kapila YL. Nisin, an apoptogenic bacteriocin and food preservative, attenuates HNSCC tumorigenesis via CHAC1. Cancer Med. 2012;1 (3):295-305. doi:10.1002/cam4.35

105. Nabofa WEE, Alashe OO, Oyeyemi OT, et al. Cardioprotective effects of curcumin-nisin based poly lactic acid nanoparticle on myocardial infarction in guinea pigs. Sci Rep. 2018;8(1). doi:10.1038/s41598-018-35145-5

106. Sunagawa Y, Wada H, Suzuki H, et al. A novel drug delivery system of oral curcumin markedly improves efficacy of treatment for heart failure after myocardial infarction in rats. Biol PharmBull. 2012;35(2):139-144.

107. Yadav YC, Pattnaik S, Swain K. Curcumin loaded mesoporous silica nanoparticles: assessment of bioavailability and cardioprotective effect. Drug Dev Ind Pharm. 2019;45(12):1889-1895. doi:10.1080/03639045.2019.1672717

108. Li J, Zhou Y, Zhang W, Bao C, Xie Z. Relief of oxidative stress and cardiomyocyte apoptosis by using curcumin nanoparticles. Colloids Surf B Biointerfaces. 2017;153:174-182. doi:10.1016/j. colsurfb.2017.02.023 
109. Simion V, Stan D, Constantinescu CA, et al. Conjugation of curcumin-loaded lipid nanoemulsions with cell-penetrating peptides increases their cellular uptake and enhances the antiinflammatory effects in endothelial cells. J Pharm Pharmacol. 2016;68(2):195-207. doi:10.1111/jphp.12513

110. Zhang J, Wang Y, Bao C, et al. Curcumin-loaded PEG-PDLLA nanoparticles for attenuating palmitate-induced oxidative stress and cardiomyocyte apoptosis through AMPK pathway. Int J Mol Med. 2019;44(2):672-682. doi:10.3892/ijmm.20 19.4228

111. Namdari M, Eatemadi A. Cardioprotective effects of curcumin-loaded magnetic hydrogel nanocomposite (nanocurcumin) against doxorubicin-induced cardiac toxicity in rat cardiomyocyte cell lines. Artif Cells Nanomed Biotechnol. 2017;45 (4):731-739. doi:10.1080/21691401.2016.1261033

112. Du Preez R, Pahl J, Arora M, Ravi kumar MNV, Brown L, Panchal SK. Low-dose curcumin nanoparticles normalise blood pressure in male Wistar rats with diet-induced metabolic syndrome. Nutrients. 2019;11(7):1542. doi:10.3390/nu11071 542

113. Liu Y, Liu Q, Liu Y, Ju F, Ma Q, He Q. In vivo evaluation of enhanced drug carrier efficiency and cardiac anti-hypertrophy therapeutic potential of nano-curcumin encapsulated photo-plasmonic nanoparticles combined polymerized nano-vesicles: a novel strategy. $J$ Photochem Photobiol B Biol. 2019;199:111619. doi:10.1016/j.jphotobiol.2019.111619

114. Cheng L, Sun X, Hu C, et al. In vivo early intervention and the therapeutic effects of 20 (S)-ginsenoside $\mathrm{Rg} 3$ on hypertrophic scar formation. PLoS One. 2014;9(12):12. doi:10.1371/journal. pone. 0113640

115. Li L, Ni J, Li M, et al. Ginsenoside Rg3 micelles mitigate doxorubicin-induced cardiotoxicity and enhance its anticancer efficacy. Drug Deliv. 2017;24(1):1617-1630. doi:10.1080/107175 44.2017.1391893

116. Yang L, Wang B, Gan H, et al. Enhanced oral bioavailability and anti-tumour effect of paclitaxel by 20 (s)-ginsenoside Rg3 in vivo. Biopharm Drug Dispos. 2012;33(8):425-436. doi:10.1002/ bdd. 1806

117. Chen Z-H, Li J, Liu J, et al. Saponins isolated from the root of Panax notoginseng showed significant antidiabetic effects in KK-Ay mice. Am J Chin Med. 2008;36(05):939-951. doi:10. 1142/S0192415X08006363

118. Lee J, Lee E, Kim D, Lee J, Yoo J, Koh B. Studies on absorption, distribution and metabolism of ginseng in humans after oral administration. $J$ Ethnopharmacol. 2009;122(1):143-148. doi:10. 1016/j.jep.2008.12.012

119. Zhang J, Han X, Li X, et al. Core-shell hybrid liposomal vesicles loaded with panax notoginsenoside: preparation, characterization and protective effects on global cerebral ischemia/reperfusion injury and acute myocardial ischemia in rats. Int $J$ Nanomedicine. 2012;7:4299. doi:10.2147/IJN.S32385

120. Deng Y, Yang M, Xu F, et al. Combined salvianolic acid B and ginsenoside $\mathrm{Rg} 1$ exerts cardioprotection against ischemia/reperfusion injury in rats. PLoS One. 2015;10(8):e0135435. doi:10.1371/ journal.pone. 0135435

121. Qiu J, Cai G, Liu X, Ma D. $\alpha v \beta 3$ integrin receptor specific peptide modified, salvianolic acid $\mathrm{B}$ and panax notoginsenoside loaded nanomedicine for the combination therapy of acute myocardial ischemia. Biomed Pharmacother. 2017;96:1418-1426. doi:10.1016/j.biopha.2017.10.086

122. Yoo JS, Lee J, Jung JH, et al. SPECT/CT imaging of high-risk atherosclerotic plaques using integrin-binding RGD dimer peptides. Sci Rep. 2015;5(1):11752. doi:10.1038/srep11752

123. Ikram M. A review on the chemical and pharmacological aspects of genus Berberis. Planta Med. 1975;28(08):353-358. doi:10. 1055/s-0028-1097869
124. Pérez-Rubio KG, González-Ortiz M, Martínez-Abundis E, Robles-Cervantes JA, Espinel-Bermúdez MC. Effect of berberine administration on metabolic syndrome, insulin sensitivity, and insulin secretion. Metab Syndr Relat Disord. 2013;11 (5):366-369. doi:10.1089/met.2012.0183

125. Gautam R, Jachak SM. Recent developments in anti-inflammatory natural products. Med Res Rev. 2009;29 (5):767-820. doi:10.1002/med.20156

126. Huang Z, Han Z, Ye B, et al. Berberine alleviates cardiac ischemia/reperfusion injury by inhibiting excessive autophagy in cardiomyocytes. Eur J Pharmacol. 2015;762:1-10. doi:10.1016/ j.ejphar.2015.05.028

127. Renugadevi J, Shagirtha K. In vivo and in vitro antioxidative efficacy of naringenin on cadmium-induced toxicity in rats. Res Rev a J Toxicol. 2013;3(3):9-16.

128. Manach C, Scalbert A, Morand C, Rémésy C, Jiménez L. Polyphenols: food sources and bioavailability. Am J Clin Nutr. 2004;79(5):727-747.

129. Maity S, Mukhopadhyay P, Kundu PP, Chakraborti AS. Alginate coated chitosan core-shell nanoparticles for efficient oral delivery of naringenin in diabetic animals-An in vitro and in vivo approach. Carbohydr Polym. 2017;170:124-132. doi:10.1016/j. carbpol.2017.04.066

130. Shulman M, Cohen M, Soto-Gutierrez A, et al. Enhancement of naringenin bioavailability by complexation with hydroxypropoyl$\beta$-cyclodextrin. PLoS One. 2011;6(4):e18033. doi:10.1371/journal.pone. 0018033

131. Fuior EV, Deleanu M, Constantinescu CA, et al. Functional role of VCAM-1 targeted flavonoid-loaded lipid nanoemulsions in reducing endothelium inflammation. Pharmaceutics. 2019;11 (8):391. doi:10.3390/pharmaceutics 11080391

132. Yuan Y, Cao W, Hong Y, et al. Tilianin pretreatment prevents myocardial ischemia-reperfusion injury via preservation of mitochondrial function in rat heart. Phytomedicine. 2017;34:106-114. doi:10.1016/j.phymed.2017.08.007

133. Cheng XM, Ma TY, Su L, et al. Separation and authentication of tilianin and quality standards of semen of Dracocephalum moldavia. Zhongguo Zhong Yao Za Zhi. 2015;40 (10): 1845-1849.

134. Wang Y, Wang Y, Wang X, Hu P. Tilianin loaded ROS-scavenging nano-micelles protect $\mathrm{H} 9 \mathrm{c} 2$ cardiomyocyte against hypoxia/reoxygenation-induced injury. $J$ Cardiovasc Pharmacol. 2018;72(1):32-39. doi:10.1097/FJC.000000000000 0587

135. Tang M, Hu P, Zheng Q, et al. Polymeric micelles with dual thermal and reactive oxygen species (ROS)-responsiveness for inflammatory cancer cell delivery. $J$ Nanobiotechnology. 2017;15(1):39. doi:10.1186/s12951-017-0275-4

136. Han R-M, Tian Y-X, Becker EM, Andersen ML, Zhang J-P, Skibsted LH. Puerarin and conjugate bases as radical scavengers and antioxidants: molecular mechanism and synergism with $\beta$ carotene. J Agric Food Chem. 2007;55(6):2384-2391. doi:10.10 21/jf062796c

137. Wong KH, Li GQ, Li KM, Razmovski-Naumovski V, Chan K. Kudzu root: traditional uses and potential medicinal benefits in diabetes and cardiovascular diseases. $J$ Ethnopharmacol. 2011;134(3):584-607. doi:10.1016/j.jep.2011.02.001

138. Luo C-F, Yuan M, Chen M-S, et al. Determination of puerarin in rat plasma by rapid resolution liquid chromatography tandem mass spectrometry in positive ionization mode. J Chromatogr B. 2011;879(19):1497-1501. doi:10.1016/j. jchromb.2011.03.035

139. Li W, Wu J, Zhang J, et al. Puerarin-loaded PEG-PE micelles with enhanced antiapoptotic effect and better pharmacokinetic profile. Drug Deliv. 2018;25(1):827-837. doi:10.1080/107175 44.2018.1455763 
140. Li W, Wu J, Xiang D, et al. Micelles loaded with puerarin and modified with triphenylphosphonium cation possess mitochondrial targeting and demonstrate enhanced protective effect against isoprenaline-induced $\mathrm{H} 9 \mathrm{c} 2$ cells apoptosis. Int J Nanomedicine. 2019;14:8345. doi:10.2147/IJN.S219670

141. Shan D, Li J, Cai P, et al. RGD-conjugated solid lipid nanoparticles inhibit adhesion and invasion of $\alpha \mathrm{v} \beta 3$ integrinoverexpressing breast cancer cells. Drug Deliv Transl Res. 2015;5(1):15-26. doi:10.1007/s13346-014-0210-2

142. Yu J, Gu Y, Du KT, Mihardja S, Sievers RE, Lee RJ. The effect of injected RGD modified alginate on angiogenesis and left ventricular function in a chronic rat infarct model. Biomaterials. 2009;30(5):751-756. doi:10.1016/j.biomaterials.2008.09.059

143. Dong Z, Guo J, Xing X, Zhang X, Du Y, Lu Q. RGD modified and PEGylated lipid nanoparticles loaded with puerarin: formulation, characterization and protective effects on acute myocardial ischemia model. Biomed Pharmacother. 2017;89:297-304. doi:10.1016/j.biopha.2017.02.029

144. Liu X, Ding Y, Zhao B, et al. In vitro and in vivo evaluation of puerarin-loaded PEGylated mesoporous silica nanoparticles. Drug Dev Ind Pharm. 2016;42(12):2031-2037. doi:10.1080/ 03639045.2016.1190742

145. Larson A, Witman MAH, Guo Y, et al. Acute, quercetin-induced reductions in blood pressure in hypertensive individuals are not secondary to lower plasma angiotensin-converting enzyme activity or endothelin-1: nitric oxide. Nutr Res. 2012;32(8):557-564. doi:10.1016/j.nutres.2012.06.018

146. Cai X, Fang Z, Dou J, Yu A, Zhai G. Bioavailability of quercetin: problems and promises. Curr Med Chem. 2013;20 (20):2572-2582. doi:10.2174/09298673113209990120

147. Soloviev A, Stefanov A, Parshikov A, et al. Arrhythmogenic peroxynitrite-induced alterations in mammalian heart contractility and its prevention with quercetin-filled liposomes. Cardiovasc Toxicol. 2002;2(2):129-139. doi:10.1385/CT:2:2:129

148. Cote B, Carlson LJ, Rao DA, Alani AWG. Combinatorial resveratrol and quercetin polymeric micelles mitigate doxorubicin induced cardiotoxicity in vitro and in vivo. $J$ Control Release. 2015;213:128-133. doi:10.1016/j.jconrel.2015.06.040

149. Lozano O, Lázaro-Alfaro A, Silva-Platas C, et al. Nanoencapsulated quercetin improves cardioprotection during hypoxia-reoxygenation injury through preservation of mitochondrial function. Oxid Med Cell Longev. 2019;2019:1-14. doi:10.1155/2019/7683051

150. Wang L, Feng M, Li Y, et al. Fabrication of superparamagnetic nano-silica@quercetin-encapsulated PLGA nanocomposite: potential application for cardiovascular diseases. JPhotochem Photobiol B Biol. 2019;196:111508. doi:10.1016/j.jphotobiol.2019.05.005

151. Waisundara VY, Hsu A, Tan BK-H, Huang D. Baicalin improves antioxidant status of streptozotocin-induced diabetic Wistar rats. J Agric Food Chem. 2009;57(10):4096-4102. doi:10.1021/ jf8028539

152. Kong F, Luan Y, Zhang Z, Cheng G, Qi T, Sun C. Baicalin protects the myocardium from reperfusion-induced damage in isolated rat hearts via the antioxidant and paracrine effect. Exp Ther Med. 2014;7(1):254-259. doi:10.3892/etm.2013.1369

153. Zhang S, Wang J, Pan J. Baicalin-loaded PEGylated lipid nanoparticles: characterization, pharmacokinetics, and protective effects on acute myocardial ischemia in rats. Drug Deliv. 2016;23(9):3696-3703. doi:10.1080/10717544.2016.1223218

154. Pangeni R, Sahni JK, Ali J, Sharma S, Baboota S. Resveratrol: review on therapeutic potential and recent advances in drug delivery. Expert Opin Drug Deliv. 2014;11(8):1285-1298. doi:10.1517/17425247.2014.919253

155. Cottart C, Nivet-Antoine V, Laguillier-Morizot C, Beaudeux J. Resveratrol bioavailability and toxicity in humans. Mol Nutr Food Res. 2010;54(1):7-16. doi:10.1002/mnfr.200900437
156. Shahraki A, Bahadorikhalili S, Hashemzaei M, et al. Resveratrol nanocapsule as an efficient tool for blood pressure regulation: a study on metabolic syndrome induced mice. Biosci Biotechnol Res Commun. 2017;10(4):623-630. doi:10.21786/bbrc/10.4/4

157. Carlson LJ, Cote B, Alani AWG, Rao DA. Polymeric micellar co-delivery of resveratrol and curcumin to mitigate in vitro doxorubicin-induced cardiotoxicity. J Pharm Sci. 2014;103 (8):2315-2322. doi:10.1002/jps.24042

158. Zhang L, Zhu K, Zeng H, et al. Resveratrol solid lipid nanoparticles to trigger credible inhibition of doxorubicin cardiotoxicity. Int J Nanomedicine. 2019;14:6061. doi:10.2147/IJN.S211130

159. Fei X, Chen X, Liang G, et al. Preparation, characterization, and biodistribution of breviscapine proliposomes in heart. J Drug Target. 2009;17(5):408-414. doi:10.1080/10611860902913380

160. Lu J, Cheng C, Zhao X, et al. PEG-scutellarin prodrugs: synthesis, water solubility and protective effect on cerebral ischemia/ reperfusion injury. Eur J Med Chem. 2010;45(5):1731-1738. doi:10.1016/j.ejmech.2010.01.006

161. Xiong F, Wang H, Geng K, Gu N, Zhu J. Optimized preparation, characterization and biodistribution in heart of breviscapine lipid emulsion. Chem Pharm Bull. 2010;58(11):1455-1460. doi:10.12 48/cpb.58.1455

162. Lee Y-J, Lee YM, Lee C-K, Jung JK, Han SB, Hong JT. Therapeutic applications of compounds in the Magnolia family. Pharmacol Ther. 2011;130(2):157-176. doi:10.1016/j. pharmthera.2011.01.010

163. Yang S, Hsieh M, Tsai T, Hsu S. Effector mechanism of magnolol-induced apoptosis in human lung squamous carcinoma $\mathrm{CH} 27$ cells. Br J Pharmacol. 2003;138(1):193-201. doi:10.1038/sj.bjp. 0705024

164. Amorati R, Zotova J, Baschieri A, Valgimigli L. Antioxidant activity of magnolol and honokiol: kinetic and mechanistic investigations of their reaction with peroxyl radicals. $J$ Org Chem. 2015;80(21):10651-10659. doi:10.1021/acs.joc.5b01772

165. Yang B, Xu Y, Yu S, Huang Y, Lu L, Liang X. Anti-angiogenic and anti-inflammatory effect of Magnolol in the oxygen-induced retinopathy model. Inflamm Res. 2016;65(1):81-93. doi:10.1007/ s00011-015-0894-X

166. Liang X, Xing W, He J, et al. Magnolol administration in normotensive young spontaneously hypertensive rats postpones the development of hypertension: role of increased PPAR gamma, reduced TRB3 and resultant alleviative vascular insulin resistance. PLoS One. 2015;10(3).

167. Liang C-J, Lee C-W, Sung H-C, et al. Magnolol reduced TNF- $\alpha-$ induced vascular cell adhesion molecule-1 expression in endothelial cells via JNK/p38 and NF- $\mathrm{BB}$ signaling pathways. Am J Chin Med. 2014;42(03):619-637. doi:10.1142/S0192415X14500402

168. Chen $\mathrm{CY}, \mathrm{Wu} \mathrm{C}$. Magnolol encapsulated by liposome in inhibiting smooth muscle cell proliferation. J Chinese Chem Soc. 2008;55(3):517-521. doi:10.1002/jccs.200800076

169. Lee C-W, Hu -SC-S, Yen F-L, et al. Magnolol nanoparticles exhibit improved water solubility and suppress TNF- $\alpha$-induced VCAM-1 expression in endothelial cells. J Biomed Nanotechnol. 2017;13(3):255-268. doi:10.1166/jbn.2017.2342

170. Ananingsih VK, Sharma A, Zhou W. Green tea catechins during food processing and storage: a review on stability and detection. Food Res Int. 2013;50(2):469-479. doi:10.1016/j.foodres.2011. 03.004

171. Hong MH, Kim MH, Chang HJ, et al. (-)-Epigallocatechin-3-gallate inhibits monocyte chemotactic protein-1 expression in

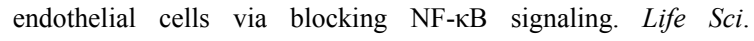
2007;80(21):1957-1965. doi:10.1016/j.1fs.2007.02.024

172. Hong J, Lu H, Meng X, Ryu J-H, Hara Y, Yang CS. Stability, cellular uptake, biotransformation, and efflux of tea polyphenol (-)-epigallocatechin-3-gallate in HT-29 human colon adenocarcinoma cells. Cancer Res. 2002;62(24):7241-7246. 
173. Zhang J, Nie S, Martinez-Zaguilan R, Sennoune SR, Wang S. Formulation, characteristics and antiatherogenic bioactivities of CD36-targeted epigallocatechin gallate (EGCG)-loaded nanoparticles. J Nutr Biochem. 2016;30:14-23. doi:10.1016/j. jnutbio.2015.11.001

174. Zhang J, Nie S, Wang S. Nanoencapsulation enhances epigallocatechin-3-gallate stability and its antiatherogenic bioactivities in macrophages. J Agric Food Chem. 2013;61(38): 9200-9209. doi:10.1021/jf4023004

175. Feng J, Li S, Chen H. Tanshinone IIA inhibits myocardial remodeling induced by pressure overload via suppressing oxidative stress and inflammation: possible role of silent information regulator 1. Eur J Pharmacol. 2016;791:632-639. doi:10.1016/j. ejphar.2016.09.041

176. Gao S, Liu Z, Li H, Little PJ, Liu P, Xu S. Cardiovascular actions and therapeutic potential of tanshinone IIA. Atherosclerosis. 2012;220(1):3-10. doi:10.1016/j.atherosclerosis.2011.06.041

177. Li J, Liu P, Liu J-P, Zhang W-L, Yang J-K, Fan Y-Q. Novel Tanshinone II A ternary solid dispersion pellets prepared by a single-step technique: in vitro and in vivo evaluation. Eur J Pharm Biopharm. 2012;80(2):426-432. doi:10.1016/j.ejpb.20 11.11 .003

178. Zhang W, He H, Liu J, et al. Pharmacokinetics and atherosclerotic lesions targeting effects of tanshinone IIA discoidal and spherical biomimetic high density lipoproteins. Biomaterials. 2013;34 (1):306-319. doi:10.1016/j.biomaterials.2012.09.058

179. Zhang S, Li J, Hu S, Wu F, Zhang X. Triphenylphosphonium and D- $\alpha$-tocopheryl polyethylene glycol 1000 succinate-modified, tanshinone IIA-loaded lipid-polymeric nanocarriers for the targeted therapy of myocardial infarction. Int $J$ Nanomedicine. 2018;13:4045. doi:10.2147/IJN.S165590

180. Mao S, Wang L, Chen P, Lan Y, Guo R, Zhang M. Nanoparticlemediated delivery of Tanshinone IIA reduces adverse cardiac remodeling following myocardial infarctions in a mice model: role of NF-кB pathway. Artif Cells Nanomed Biotechnol. 2018;46(sup3):S707-S716. doi:10.1080/21691401.2018.1508028

181. Badore N, Das P, Pillai S, Thakur A. Role of Ginkgo biloba extract, against isoproterenol induced cardiac toxicity in rats. Indian J Pharm Educ Res. 2017;51(4s):s691-s699. doi:10.5530/ ijper. $51.4 \mathrm{~s} .100$

182. Oyama Y, Fuchs PA, Katayama N, Noda K. Myricetin and quercetin, the flavonoid constituents of Ginkgo biloba extract, greatly reduce oxidative metabolism in both resting and $\mathrm{Ca}(2+)$-loaded brain neurons. Brain Res. 1994;635(1-2):125-129. doi:10.1016/ 0006-8993(94)91431-1
183. Roy S, Chaudhuri T. A quantitative assessment of bioactive phytochemicals of Nerium indicum: an ethnopharmacological herb. Int J Res Pharm Sci. 2012;3:579-587.

184. Ahmed Q, Gupta N, Kumar A, Nimesh S. Antibacterial efficacy of silver nanoparticles synthesized employing Terminalia arjuna bark extract. Artif Cells Nanomed Biotechnol. 2017;45(6):1-9. doi:10.1080/21691401.2016.1215328

185. Aqil F, Ahmad I, Mehmood Z. Antioxidant and free radical scavenging properties of twelve traditionally used Indian medicinal plants. Turkish J Biol. 2006;30:177-183.

186. Aa A, Pb K, Pattiyappan S, Ra U, Peo R. Phytochemical screening of Sesbania grandiflora (Linn). Int $J$ Biosci Nanosci. 2014;1:2014.

187. Hamid K, Ng I, Tallapragada VJ, et al. An investigation of the differential effects of ursane triterpenoids from Centella asiatica, and their semisynthetic analogues, on GABAA receptors. Chem Biol Drug Des. 2016;88(3):386-397. doi:10.1111/cbdd.12766

188. Mridula K, Parthibhan S, Kumar T, Rao M. In vitro organogenesis from Tinospora cordifolia (Willd.) Miers — a highly valuable medicinal plant. $S$ Afr J Bot. 2017;113:84-90. doi:10.1016/j. sajb.2017.08.003

189. Upadhyay AK, Kumar K, Kumar A, Mishra HS. Tinospora cordifolia (Willd.) Hook. f. and Thoms. (Guduchi) - validation of the Ayurvedic pharmacology through experimental and clinical studies. Int J Ayurveda Res. 2010;1(2):112-121. doi:10.4103/ 0974-7788.64405

190. Nitika G, Meena A, Jaspreet N. Evaluation of physicochemical and preliminary phytochemical studies on the root of bombax ceiba linn. Int Res J Pharm. 2011;924-926.

191. Patel S, Verma N, Rathore B, Nayak G, Singhai A, Singh P. Cardioprotective effect of Bombax ceiba flowers against acute adriamycin-induced myocardial infarction in rats. Rev Bras Farmacogn. 2011;21(4):704-709. doi:10.1590/S0102-695X2011 005000090

192. Helal AM, Nakamura N, El-Askary H, Hattori M. Sesquiterpene lactone glucosides from Sonchus asper. Phytochemistry. 2000;53 (4):473-477. doi:10.1016/S0031-9422(99)00516-6

193. Khan M. Prevention of KBrO3-induced cardiotoxicity by Sonchus asper in rat. J Med Plant Res. 2011.

194. Juhasz B, Kertesz A, Balla J, et al. Cardioprotective effects of sour cherry seed extract (SCSE) on the hypercholesterolemic rabbit heart. Curr Pharm Des. 2013;19(39):6896-6905. doi:10.2174/138161281939131127120517

195. Yaqoob D. Paeonia Emodi: An Ethnopharmacological and Phytochemical Review. 2017.
International Journal of Nanomedicine

\section{Publish your work in this journal}

The International Journal of Nanomedicine is an international, peerreviewed journal focusing on the application of nanotechnology in diagnostics, therapeutics, and drug delivery systems throughout the biomedical field. This journal is indexed on PubMed Central, MedLine, CAS, SciSearch ${ }^{\mathbb{2}}$, Current Contents ${ }^{\mathbb{R}} /$ Clinical Medicine, $^{2}$
Journal Citation Reports/Science Edition, EMBase, Scopus and the Elsevier Bibliographic databases. The manuscript management system is completely online and includes a very quick and fair peer-review system, which is all easy to use. Visit http://www.dovepress.com/ testimonials.php to read real quotes from published authors. 